\title{
Effects of Montmorillonite on the Mineralization and Cementing Properties of Microbiologically Induced Calcium Carbonate
}

\author{
Tao Chen, ${ }^{1}$ Jiwei Li, ${ }^{1}$ Peiheng Shi, ${ }^{2}$ Yi Li, ${ }^{1}$ Jia Lei, ${ }^{2}$ Jian Zhou, ${ }^{2}$ Zuowen Hu, ${ }^{3}$ Tao Duan, \\ Yongjian Tang, ${ }^{2}$ and Wenkun $\mathrm{Zhu}^{1,2}$ \\ ${ }^{1}$ Nuclear Waste and Environmental Safety Key Laboratory of Defense, Southwest University of Science and Technology, \\ Mianyang 621010, China \\ ${ }^{2}$ Sichuan Civil-Military Integration Institute, Mianyang, Sichuan 621010, China \\ ${ }^{3}$ China Academy of Engineering Physics, Mianyang 621000, China \\ Correspondence should be addressed to Wenkun Zhu; zhuwenkun@swust.edu.cn
}

Received 26 June 2017; Revised 19 August 2017; Accepted 7 September 2017; Published 9 October 2017

Academic Editor: Angela De Bonis

Copyright (C) 2017 Tao Chen et al. This is an open access article distributed under the Creative Commons Attribution License, which permits unrestricted use, distribution, and reproduction in any medium, provided the original work is properly cited.

\begin{abstract}
Carbonate mineralization microbe is a microorganism capable of decomposing the substrate in the metabolic process to produce the carbonate, which then forms calcium carbonate with calcium ions. By taking advantage of this process, contaminative uranium tailings can transform to solid cement, where calcium carbonate plays the role of a binder. In this paper, we have studied the morphology of mineralized crystals by controlling the mineralization time and adding different concentrations of montmorillonite (MMT). At the same time, we also studied the effect of carbonate mineralized cementation uranium tailings by controlling the amount of MMT. The results showed that MMT can regulate the crystal morphology of calcium carbonate. What is more, MMT can balance the acidity and ions in the uranium tailings; it also can reduce the toxicity of uranium ions on microorganisms. In addition, MMT filling in the gap between the uranium tailings made the cement body more stable. When the amount of MMT is $6 \%$, the maximum strength of the cement body reached $2.18 \mathrm{MPa}$, which increased by $47.66 \%$ compared with that the sample without MMT. Therefore, it is reasonable and feasible to use the MMT to regulate the biocalcium carbonate cemented uranium tailings.
\end{abstract}

\section{Introduction}

Biomineralization refers to the process by which organisms produce inorganic minerals through the regulation of biological macromolecules [1]. Microorganisms play an important role in the process of biomineralization, which is the largest and most widely distributed form of life on earth. It has the ability to induce mineral deposition such as carbonic acid/phosphoric acid/sulphate. Microbial-induced mineralization mainly can be defined as the mineralization process caused by the interaction of microbial life activities with the surrounding environment [2]. Soil mineral-microbial interactions are the most basic biogeochemical effects $[3,4]$. Microbial metabolic activities play an important role in the elemental cycling, formation, and transformation, as well as the weathering of the earth's environment [5]. In recent years, the interaction between soil minerals and microbes has become a hot topic in related disciplines. In 2016, Shi et al. published a review in the Journal of Nature Review on microbes [6], which systematically summarized the mechanism of interaction between minerals and microbes, focusing on two basic sciences of energy and extracellular electron transfer. In addition, domestic and foreign scholars have studied the different systems and related mechanism of soil mineral-microbial interaction, involving the microbial adsorption process on the surface of minerals $[7,8]$; they also studied the relationship between mineral-microbial-soil contaminants.

At present, there are many studies on the interaction between soil clay minerals and microorganisms, involving clay minerals including montmorillonite (MMT), bentonite, kaolin, hydrotalcite, and illite [9]. Among these clay minerals, 
TABLE 1: $\gamma$-radiation dose rate of uranium tailings; unit: $\mu \mathrm{Gy} / \mathrm{h}$.

\begin{tabular}{lccccc}
\hline Distance $(\mathrm{cm})$ & Sample 1 & Sample 2 & Sample 3 & Sample 4 & Sample 5 \\
\hline 0 & 0.2339 & 0.2795 & 0.2574 & 0.2608 & 0.2612 \\
50 & 0.1416 & 0.1414 & 0.1418 & 0.1508 & 0.1542 \\
100 & 0.1442 & 1.1412 & 1.1415 & 0.1428 & 0.1451 \\
\hline
\end{tabular}

MMT and microbial interaction research is one of the hot spots of concern. MMT belongs to the layered silicate clay minerals. MMT has a good adsorption, ion exchange, which is retained on the radionuclide, blocking the migration of nuclides. MMT is widely used for radionuclide pollution controlling and repairing as a green environment-friendly material $[10,11]$. At the cellular level, MMT undergoes a series of interactions with microorganisms, including adsorption, aggregation, nucleation, and mineralization [12]. The reason is that the surface of bacteria is easy to dissolve ions or induce a variety of mineral ion nucleation, so as to achieve the purpose of adsorption or mineralization [13]. At the same time, MMT can effectively protect the growth of microorganisms by buffering the $\mathrm{pH}$ of the system. In addition, MMT was used as microbial nucleation sites to promote mineral deposition.

In today's society, with the continuous development of nuclear energy, uranium tailings, and other wastes more and more from the nuclear fuel production process, a large number of uranium tailings have become a long potential for radioactive sources [14]. Uranium tailings contain many radionuclides, heavy metal poisons, and certain salts. Uranium tailings will seriously endanger the surrounding ecological environment and human health. Therefore, it is necessary to explore a low-cost, effective, and easy-to-use treatment of uranium tailings.

As early as 1973, Boquet et al. [15] found that soil bacteria induced calcite crystal deposition phenomenon; this phenomenon of microbial mineralization has aroused the concern of scholars at home and abroad. Researchers have found that carbonate mineralization plays an important role in the natural diagenesis process [16]. Minerals can be used to form mineral calcium carbonate crystals (composed of bacteria, cell secretions, and calcium carbonate) [17]. Microbes can cement the surrounding loose debris material into a hard rock through the role of an organic matrix $[18,19]$. For example, carbonate mineralization can be used to carry out the sand body cementation test, according to researchers at the University of Murdoch in Australia [20]. In another study, van Paassen et al. [21] used microbial grouting reinforcement technology to study the mineralization cementation of bacteria and gravel. Based on the above inspiration, biocalcium carbonate cemented loose particles which can be used as a new and environmentally friendly cementing material have been paid tremendous attention by scholars at home and abroad $[20,22]$. However, the microbial and mineral synergistic cementation sand bodies are rarely reported.

Based on the above-mentioned enlightenment, we have studied the morphology of mineralized crystals by controlling the mineralization time and concentrations of MMT. At the same time, we also investigated the effect of carbonate mineralized cementation uranium tailings by controlling the amount of MMT. It is expected to provide theoretical support and scientific basis for the application of biocalcium carbonate cementing technology in uranium tailings. Through the in situ cementing of biocalcium carbonate, it is necessary to avoid the shortcomings of high-energy, high-emission, and field construction in the traditional high-pressure grouting cementing process, which is higher for the equipment and the influence on the surrounding environment. At the same time, biocalcium carbonate cementing technology provides some reference for disposal of other tailings and radioactive solid waste.

\section{Materials and Methods}

\subsection{Materials}

2.1.1. Uranium Tailings. Uranium tailings are taken from Hengyang (Hunan). The radioactive was measured by Gamma Spectrometer System (ORTEC). The gamma radiation dose rate of uranium tailings is shown in Table 1.

The radioactive background level is in the range of 42.9-92.6 $\mathrm{nGy} / \mathrm{h}$, and the radioactivity of uranium tailings is in the range of $0.1412 \sim 0.2795 \mu \mathrm{Gy} / \mathrm{h}$.

2.1.2. Reagents. Reagents contain calcium nitrate (analytical grade, Chengdu Cologne Chemical Co., Ltd.), peptone (analytical grade, Sinopharm Group Pharmaceutical Co., Ltd.), $\mathrm{NaCl}$ (analytical grade, Chengdu Cologne Chemical Co., Ltd.), glucose (Analytical Pure, Sinopharm Group Pharmaceutical Co., Ltd.), anhydrous ethanol (analytical grade, Chengdu Cologne Chemical Co., Ltd.), and deionized water.

\subsection{Methods}

2.2.1. Strain Culture. Bacillus pasteurii was inoculated into beef extract-peptone agar medium (beef extract $10 \mathrm{~g} / \mathrm{L}$, peptone $5 \mathrm{~g} / \mathrm{L}$, sodium chloride $5 \mathrm{~g} / \mathrm{L}, \mathrm{H}_{2} \mathrm{O} 1 \mathrm{~L}$, agar $15 \mathrm{~g} / \mathrm{L}$, and $\mathrm{pH}$ value 8.0). Bacillus pasteurii was inoculated into a liquid medium (glucose $20 \mathrm{~g} / \mathrm{L}$, peptone $10 \mathrm{~g} / \mathrm{L}$, sodium chloride $10 \mathrm{~g} / \mathrm{L}, \mathrm{H}_{2} \mathrm{O} 1 \mathrm{~L}$, and $\mathrm{pH} 8.0$ ). The bacteria were cultured in a biochemical incubator at $30^{\circ} \mathrm{C}$ for $24 \mathrm{~h}$.

2.2.2. Mineralization Experiments. $1 \mathrm{~L}$ of liquid medium was prepared using deionized water, glucose $20 \mathrm{~g}$, peptone $10 \mathrm{~g}$, and $\mathrm{NaCl} 5 \mathrm{~g}$. And $0.05 \mathrm{~mol} / \mathrm{L}(\mathrm{C} 1), 0.1 \mathrm{~mol} / \mathrm{L}(\mathrm{C} 2)$, and $0.15 \mathrm{~mol} / \mathrm{L}(\mathrm{C} 3)$ of $\mathrm{Ca}^{2+} /$ urea through the microporous membrane filter sterilization method added to the above liquid medium. The liquid medium was incubated at $30^{\circ} \mathrm{C}$ for 12,24 , and $48 \mathrm{~h}$, respectively. The mineralized sample was 
obtained by static and suction filtration, and the mineralized sample was washed three times with distilled water and absolute ethanol and then dried at $45^{\circ} \mathrm{C}$ for $24 \mathrm{~h}$.

2.2.3. Preparation of Monolayer MMT Solution. $10 \mathrm{~g}$ of MMT was dissolved in $1 \mathrm{~L}$ of deionized water and stirred at $400 \mathrm{rpm} / \mathrm{min}$ for one week. And then the solution was centrifuged at $3000 \mathrm{rpm}$ for $10 \mathrm{~min}$. The supernatant was the desired monolayer MMT solution.

2.2.4. Mineralization Experiment by Synergistic MMT. The liquid medium was added to $10 \mathrm{ml}$ of sterilized monolayer MMT solution, and then $5 \mathrm{~mL}$ of bacterial liquid was inoculated, respectively. The liquid medium was incubated at $30^{\circ} \mathrm{C}$ for 12,24 , and $48 \mathrm{~h}$, respectively. The mineralized sample was obtained by static and suction filtration, and the mineralized sample was washed three times with distilled water and absolute ethanol and then dried.

\subsubsection{Mineralization Experiment by Adjusting the Temper-} ature and $p H .1 \mathrm{~L}$ of liquid medium was prepared using deionized water, glucose $20 \mathrm{~g}$, peptone $10 \mathrm{~g}$, and $\mathrm{NaCl} 5 \mathrm{~g}$. And $0.1 \mathrm{~mol} / \mathrm{L}$ of $\mathrm{Ca}^{2+} /$ urea through the microporous membrane filter sterilization method added to the above liquid medium. $\mathrm{pH}$ was adjusted to $6.0,7.0,8.0,9.0$, and 10.0 , respectively. The liquid medium was incubated at $30^{\circ} \mathrm{C}$ for $24 \mathrm{~h}$.

$1 \mathrm{~L}$ of liquid medium was prepared using deionized water, glucose $20 \mathrm{~g}$, peptone $10 \mathrm{~g}$, and $\mathrm{NaCl} 5 \mathrm{~g}$. And $0.1 \mathrm{~mol} / \mathrm{L}$ of $\mathrm{Ca}^{2+}$ /urea through the microporous membrane filter sterilization method added to the above liquid medium. Temperature was adjusted to $10^{\circ} \mathrm{C}, 20^{\circ} \mathrm{C}, 30^{\circ} \mathrm{C}, 40^{\circ} \mathrm{C}$, and $50^{\circ} \mathrm{C}$, respectively. The liquid medium was incubated for $24 \mathrm{~h}$.

2.2.6. Cementing of Uranium Tailings. The bottom of the $10 \mathrm{~mL}$ cylindrical plastic syringe out of the plug is filled with $1 \mathrm{~cm}$ thick medical gauze. The mixed homogeneous uranium tailings are injected into the syringe, the mass fraction of MMT in the mixed homogeneous uranium tailings was $0 \%$, $2 \%, 4 \%, 6 \%$, and $8 \%$, and then the liquid medium was added to the syringe. The mineralization fluid was injected into the syringe after $12 \mathrm{~h}$; after a certain period of time, the cemented sand column is made by stripping drying.

2.3. Characterization. The mineralized samples amplified 1000-20000 times were observed by the SEM. The crystal forms were analyzed by X-ray diffraction analyzer, $\mathrm{Cu} \mathrm{K} \alpha$ radiation, wavelength $1.54056 \AA$, tube voltage $40.0 \mathrm{kV}$, tube current $100 \mathrm{~mA}$, scan range $3^{\circ}-80^{\circ}$, and scan step $0.02^{\circ}$. In the temperature range of $40-900^{\circ} \mathrm{C}$, mineralized samples were characterized by TG at the heating rate of $20^{\circ} \mathrm{C} / \mathrm{min}$. XPS analyses were carried out with a Kratos Axis Ultra (Kratos Analytical, Manchester, UK) photoelectron spectrometer. The instrument uses a monochromatic $\mathrm{Al} \mathrm{K} \alpha \mathrm{X}$-ray source. FT-IR spectra of mineralized samples were taken by Nicolet Avatar 370 of FT-IR spectrometer (Thermo Nicolet, USA) at wavenumbers from 4000 to $400 \mathrm{~cm}^{-1}$. The products mixed with $\mathrm{KBr}$ were compressed into tablet and analyzed by infrared spectroscopy, resolving power $4 \mathrm{~cm}^{-1}$, scanning 20 times, scanning range of $4000-400 \mathrm{~cm}^{-1}$.

\section{Results and Discussion}

3.1. MMT and Carbonate Mineralization Synergistically Form Mineralized Crystals. Figures 1(a)-1(c) show the SEM images of mineralized samples by different time without MMT. It can be seen from Figures 1(a)-1(c) that calcium carbonate crystals have different sizes of spherical or spherical aggregates, which slowly transformed into regular cuboids, cuboid aggregation crystals, or irregular aggregates with increasing mineralization time; the spherical calcium carbonate crystals disappeared substantially (Figure 1(c)). Figures 1(d)-1(f) depict the SEM images of the mineralized sample by different time with MMT. At the beginning of mineralization, calcium carbonate crystals are basically spherical and spherical aggregates (Figures $1(\mathrm{~d})-1(\mathrm{f})$ ). These spherical calcium carbonate crystals are formed by the accumulation of a piece of calcium carbonate film (Supporting Information, Figure S1, in Supplementary Material available online at https://doi.org/10.1155/2017/7874251). As the mineralization time increases, the spherical crystal slowly changes into a spindle, dumbbell, and irregular polyhedron-shape crystal (Figure 1(f)).

Figures 2(a)-2(c) depict the SEM images of mineralized samples by different concentrations of $\mathrm{Ca}^{2+}$ without MMT. When the calcium ion concentration is $0.1 \mathrm{~mol} / \mathrm{L}$, the shape of the mineralized sample includes spherical, ellipsoidal, and plate type (Figure 2(b)). The shape of the mineralized samples has become almost irregular polyhedron, which was mixed with the part-spherical at $0.15 \mathrm{~mol} / \mathrm{L} \mathrm{Ca}^{2+}$ (Figure 2(c)). Figures 2(d)-2(f) depict the SEM images of the mineralized sample by different concentrations of $\mathrm{Ca}^{2+}$ with MMT. The shape of the mineralized sample includes spherical and spherical aggregates with MMT at $0.05 \mathrm{~mol} / \mathrm{L} \mathrm{Ca}^{2+}$ (Figure 2(d)). It can be seen from the surface of the mineralized sample that calcium carbonate crystals are accumulated by a piece of calcium carbonate film (Supporting Information, Figure $\mathrm{S} 1)$. With the increase of $\mathrm{Ca}^{2+}$ concentration, these spherical crystals transformed to almost square, spindle, and irregular polyhedron-shaped crystals (Figures 2(e) and 2(f)).

As can be seen from Figure 2(a), there are some holes with a mean diameter of $8 \mu \mathrm{m}$ on the samples' surface, which should be traced to death of microbe according to the size of the cell. It indicates that the microbe was involved in the formation of calcium carbonate crystals. By the SEM images, we can infer that MMT has a contribution in the regulation for calcium carbonate crystal form. At the same time, $\mathrm{Ca}^{2+}$ concentration played a certain regulating role on the morphology of calcium carbonate crystal.

Figure 3 shows the XRD patterns of calcium carbonate. According to the relevant data of PDF standard card (number 00-005-0586 and number 00-033-0268), with different $\mathrm{Ca}^{2+}$ concentration, the diffraction peak of calcite and vaterite appeared. Calcite's main diffraction angle position $2 \theta$ of $23.0^{\circ}$, $29.4^{\circ}, 35.9^{\circ}, 39.5^{\circ}, 43.1^{\circ}, 47.5^{\circ}$, and $48.5^{\circ}$ was approximately corresponding to (012), (104), (110), (113), (202), (018), and 


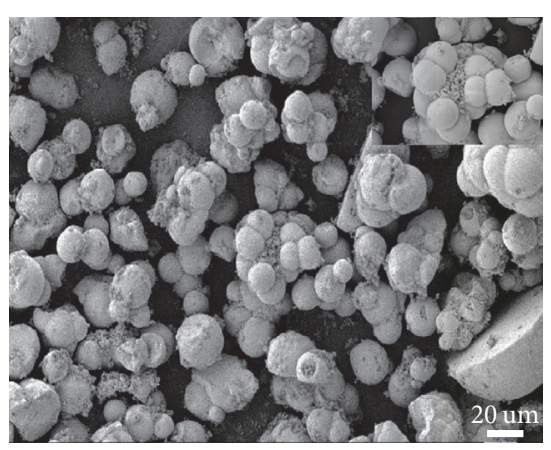

(a)

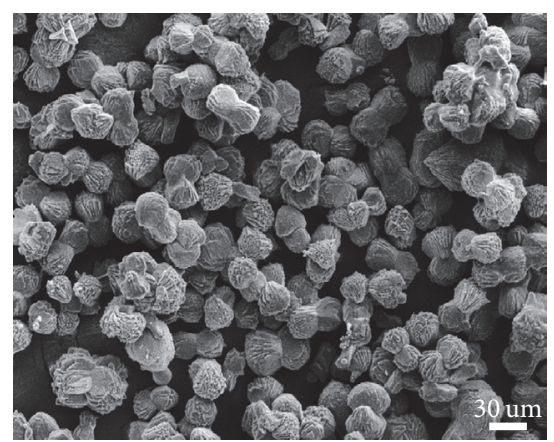

(d)

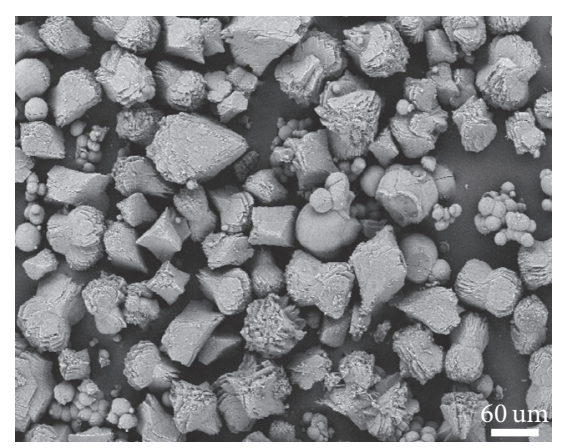

(b)

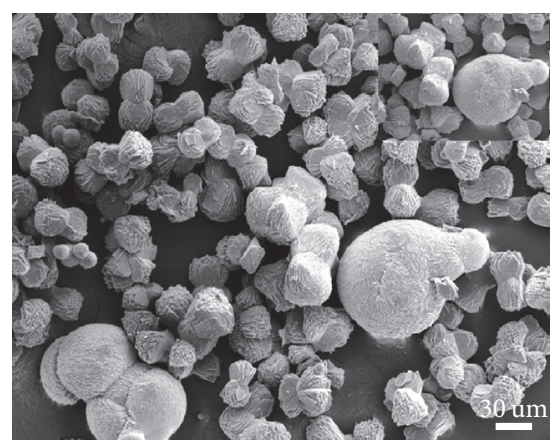

(e)

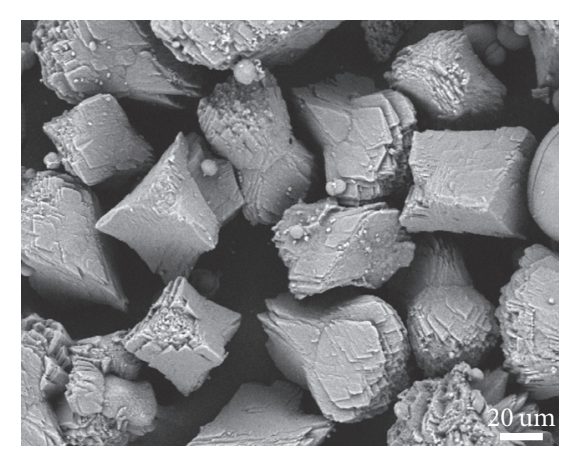

(c)

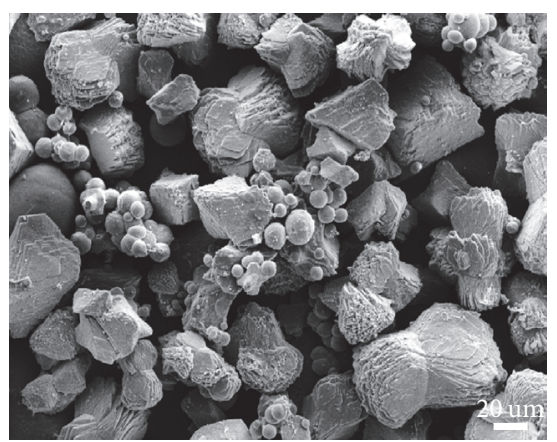

(f)

Figure 1: Typical SEM images of mineralized samples (a, b, c are mineralized samples at $0.1 \mathrm{~mol} / \mathrm{L} \mathrm{Ca}^{2+}$ and $12 \mathrm{~h}, 0.1 \mathrm{~mol} / \mathrm{L} \mathrm{Ca}^{2+}$ and $24 \mathrm{~h}$, and $0.1 \mathrm{~mol} / \mathrm{L} \mathrm{Ca}^{2+}$ and $48 \mathrm{~h}$ without MMT. $\mathrm{d}$, e, fare mineralized samples under the same conditions with MMT).

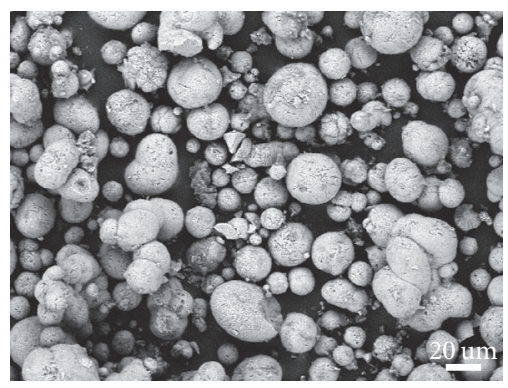

(a)

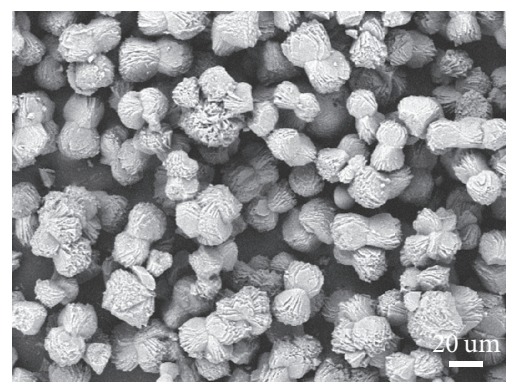

(d)

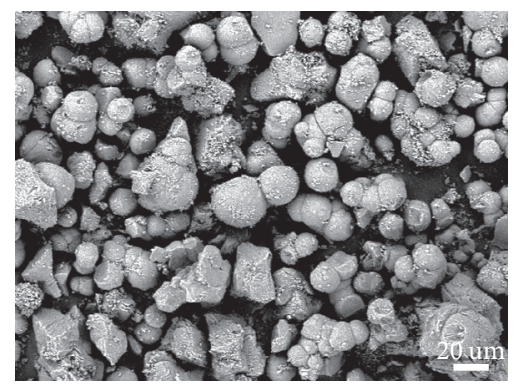

(b)

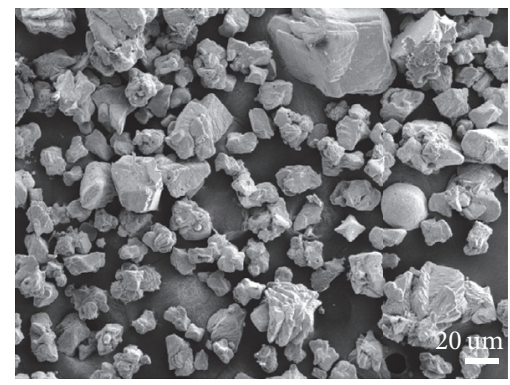

(e)

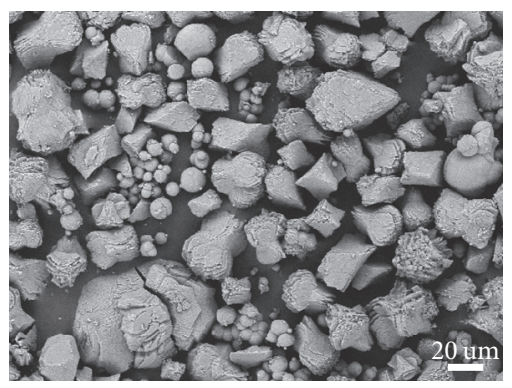

(c)

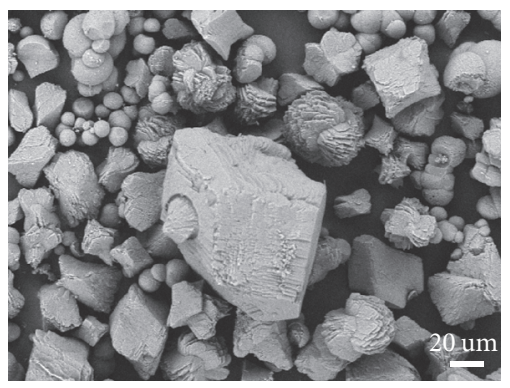

(f)

Figure 2: Typical SEM images of mineralized samples (a, b, c are mineralized samples at $0.05 \mathrm{~mol} / \mathrm{L} \mathrm{Ca}^{2+}$ and $12 \mathrm{~h}, 0.1 \mathrm{~mol} / \mathrm{L} \mathrm{Ca}{ }^{2+}$ and $12 \mathrm{~h}$, and $0.15 \mathrm{~mol} / \mathrm{L} \mathrm{Ca}^{2+}$ and $12 \mathrm{~h}$ without MMT. d, e, f are mineralized samples under the same conditions with MMT). 


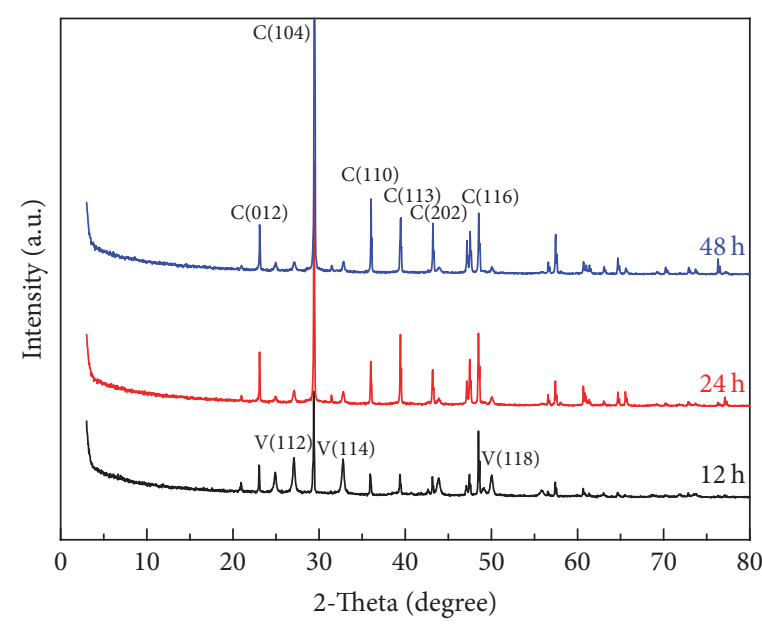

(a)

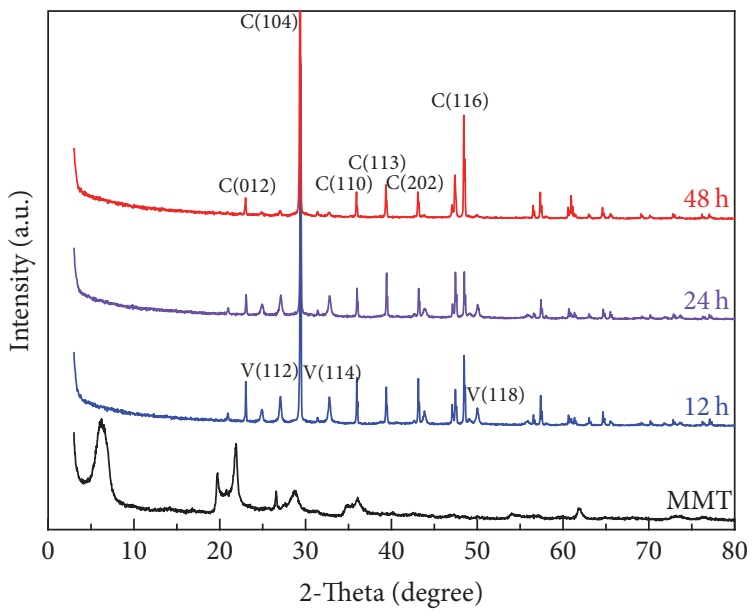

(c)

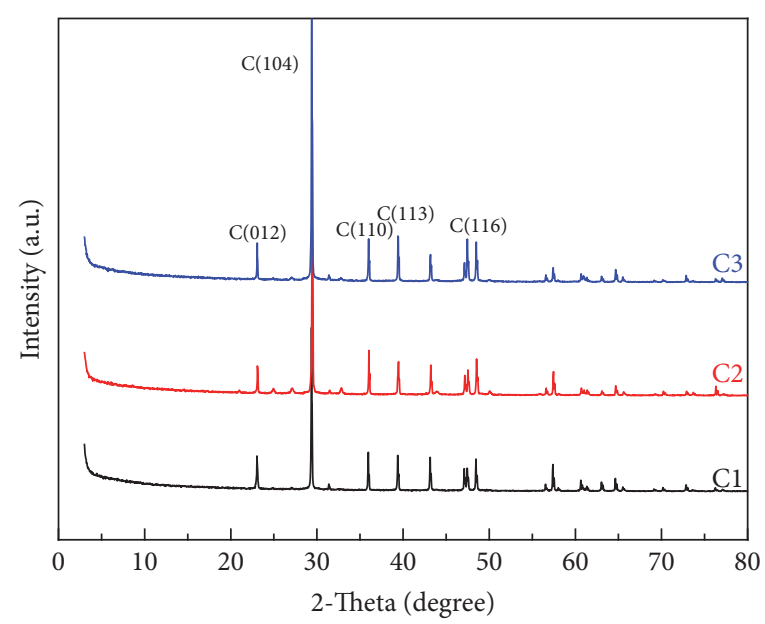

(b)

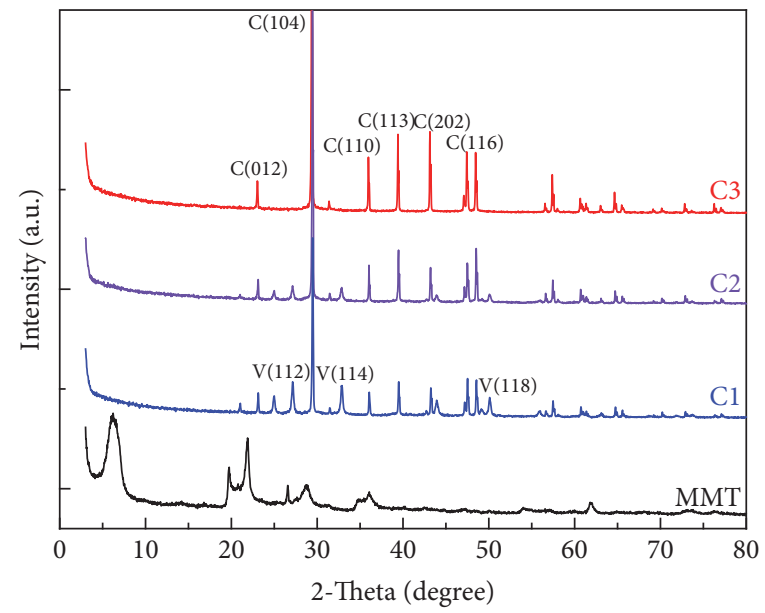

(d)

FIGURE 3: (a) XRD patterns of mineralized samples by different time without MMT, (b) XRD patterns of mineralized samples by different Ca ${ }^{2+}$ concentration without MMT, (c) XRD patterns of mineralized samples by different time with MMT, and (d) XRD patterns of mineralized samples by different $\mathrm{Ca}^{2+}$ concentration with MMT.

(116) crystal plane, respectively, and the vaterite diffraction angle position $2 \theta$ of $21.0^{\circ}, 32.7^{\circ}, 43.8^{\circ}$, and $49.0^{\circ}$ was approximately corresponding to (002), (102), (110), and (104) crystal plane, respectively (Figure 3 ). It can be seen from Figures 3(a) and 3(c) that calcite and vaterite appear in the mineralized samples at different time under the condition of $\mathrm{Ca}^{2+}$ concentration of $0.1 \mathrm{~mol} / \mathrm{L}$, regardless of whether the MMT is added [23]. And the characteristic peaks of calcite continue to increase with time. The characteristic peaks of vaterite gradually weaken and disappear (Figures 3(a) and $3(\mathrm{c})$ ). Finally, when $\mathrm{Ca}^{2+}$ concentration was $0.1 \mathrm{~mol} / \mathrm{L}$ with $48 \mathrm{~h}$, X-diffraction peak of the sample was only the one of calcite (Figures 3(a) and 3(c)) [24]. At the same mineralization time, the mineralized samples without MMT had only the characteristic peak of calcite (Figure 3(b)), while the mineralized samples with MMT coexisted with the vaterite (Figure 3(d)). However, with the increase of the concentration, the vaterite in the mineralized sample with MMT gradually disappeared, and the peak of the calcite gradually increased (Figure 3(d)). It can be seen that high $\mathrm{Ca}^{2+}$ concentration promotes the formation of calcite. All the analysis shows that MMT has a certain regulation effect on the crystal form of calcium carbonate. The XRD analysis results are consistent with the SEM morphologies.

Figure 4 illustrates the TGA data of calcium carbonate with and without MMT. Figure 4 showed that thermal decomposition behavior of calcium carbonate was similar. The whole decomposition process was accompanied by three weight loss stages [25]. The first one before $385^{\circ} \mathrm{C}$ was associated with the loss of crystal water. The second stage of the weight loss in the temperature range of $385-570^{\circ} \mathrm{C}$ corresponded to thermal decomposition of bacteria and their metabolites in the sample of the calcium carbonate. It was found that the weight loss of the mineralized samples with MMT (9.9\%) was higher than that of the mineralized samples without MMT (3.4\%). The reason may be that some of the material in the mineralized samples with MMT is decomposed. Between 570 and $800^{\circ} \mathrm{C}$, a large thermal 


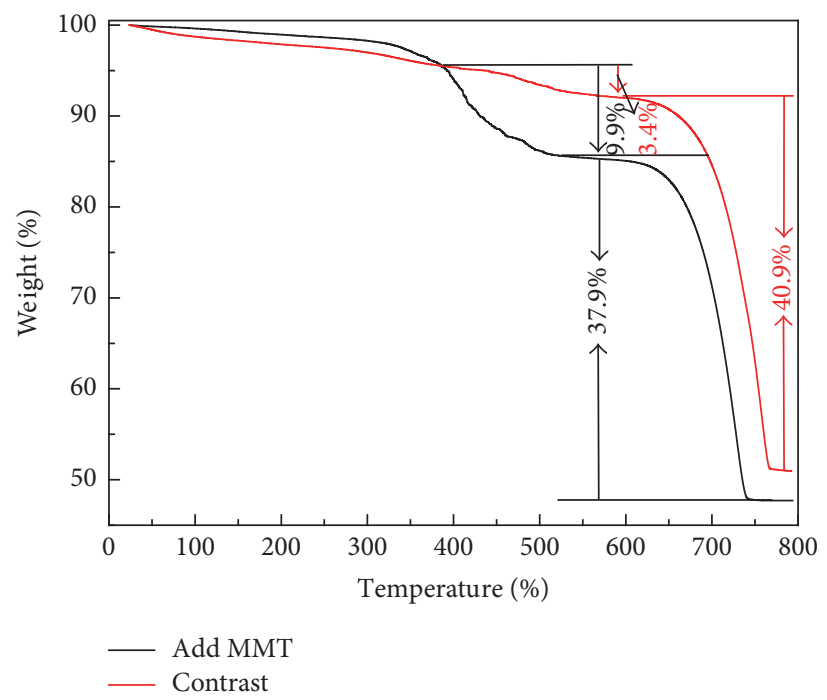

FIGURE 4: TG spectra of mineralized samples with MMT and without MMT.

TABLE 2: Binding energy data for mineralized samples.

\begin{tabular}{lccc}
\hline Sample & Element & Bonding energy $(\mathrm{eV})$ & Chemical shift $(\mathrm{eV})$ \\
\hline \multirow{2}{*}{ Mineralized samples without MMT } & O1s & 522.87 & 349.49 \\
& Ca2p & 520.62 & 2.25 \\
Mineralized samples with MMT & O1s & 332.17 & 17.32 \\
\hline
\end{tabular}

decomposition which was observed occurs, which could be attributed to the decomposition of calcium carbonate. In addition, the mineralized samples without MMT showed a more obvious weight loss than the mineralized samples with MMT.

It can be seen from Figure 4 that the weight loss rate of mineralized samples with MMT is larger than that without MMT. There are two reasons for the difference in weight loss. On the one hand, there are bits of MMT which contained some organic matter in the mineralized samples. And the decomposition of these organic substances at high temperatures leads to greater weight loss. It is found that the MMT has a large weight loss of about 200 to $500^{\circ} \mathrm{C}$ which is consistent with Xie's experimental results [26]. On the other hand, it can be seen from Table 2 that the Ca2p electron binding energy shifted from $349.49 \mathrm{eV}$ to $332.17 \mathrm{eV}$ in the mineralized sample system with MMT. The more stable material would result from higher binding energy. The lower binding energy could lead to a greater weight loss for mineralized samples with MMT. From the above discussion, we can speculate that the MMT is involved in the crystallization process of calcium carbonate.

The FT-IR spectra of calcium carbonate prepared by different $\mathrm{Ca}^{2+}$ concentrations with different time with a wavelength range of $4000-400 \mathrm{~cm}^{-1}$ are shown in Figure 5. FT-IR absorption peaks include the characteristic peaks of calcite at $870.7 / 710.4 \mathrm{~cm}^{-1}$. Moreover, the peaks at $1085.7 \mathrm{~cm}^{-1}$ belong to the vaterite peaks (Figure 5(a)), which was basically consistent with the description of the literature [27]. (Figure 5(a)), which is also in accordance with the description of literature [27]. The broad absorption peak of $3424.8 \mathrm{~cm}^{-1}$ is assigned to -O-H bond symmetric stretching vibration and asymmetric stretching vibration due to the existence of hydroxyl and adsorbed water on the surface of $\mathrm{CaCO}_{3}$ particles [28]. The peaks at $870.7 / 710.2 \mathrm{~cm}^{-1}$ are in-plane bending vibration and the out-plane bending vibration of $\mathrm{CO}_{3}{ }^{2-}$ [29]. In addition, the peak at $1425.1 \mathrm{~cm}^{-1}$ is the asymmetric stretching vibration of $\mathrm{C}=\mathrm{O}$.

As can be seen from Figure 5(a), the absorption peaks of $\mathrm{CO}_{3}{ }^{2-}$ and $\mathrm{C}=\mathrm{O}$ are increasing with the increase in mineralization time, which can show that the crystal form of calcium carbonate is changing, which is consistent with the previous XRD analysis. From Figure 5(b) it can be obtained that the characteristic peaks of the spectrum are almost the same in $\mathrm{Ca}^{2+}$ concentration of $0.05,0.1$, and $0.15 \mathrm{~mol} / \mathrm{L}$. And in $\mathrm{Ca}^{2+}$ concentration of $0.15 \mathrm{~mol} / \mathrm{L}$, the characteristic peaks were significantly higher than other concentrations. It indicates that $\mathrm{Ca}^{2+}$ concentration has a certain regulation effect on the crystal form of calcium carbonate. Figures 5(c) and 5(d) are the infrared spectra of the mineralized samples with the MMT. Compared with Figures 5(a) and 5(b), the position of the characteristic peaks shifted and the intensity of the characteristic peaks weakened. It can be seen from Figure 5(d) that when the concentration of calcium ions is $0.15 \mathrm{~mol} / \mathrm{L}$, the intensity of the characteristic peaks reaches a maximum value. We conclude that MMT played a certain regulatory role in the microbial mineralization of calcium carbonate crystals. 


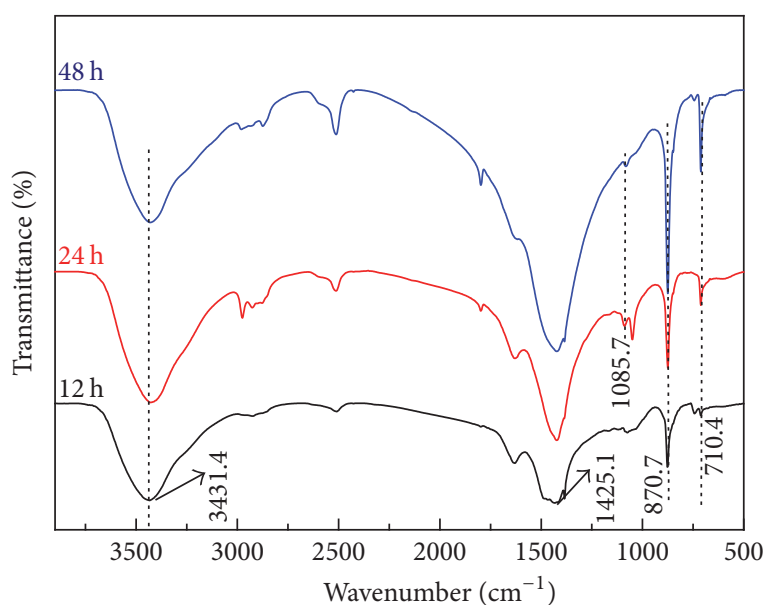

(a)

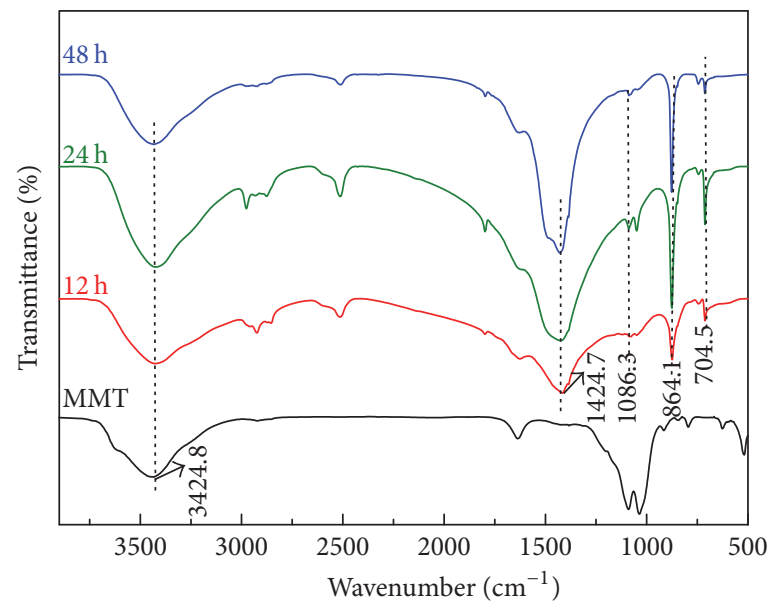

(c)

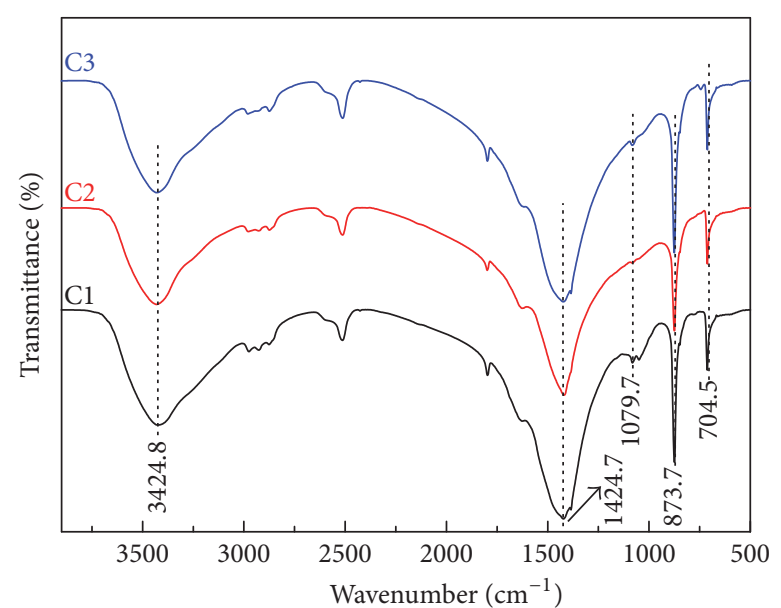

(b)

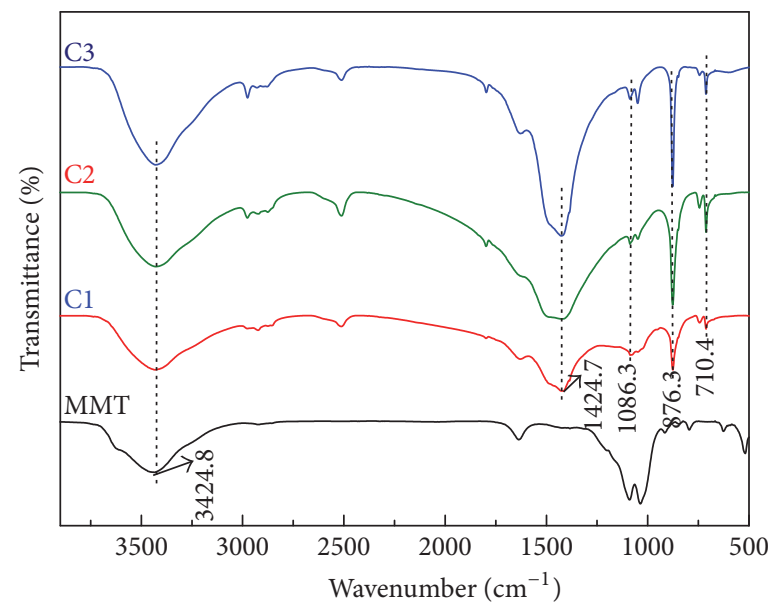

(d)

FIGURE 5: (a) FT-IR spectrum of mineralized samples b different $\mathrm{Ca}^{2+}$ concentration without MMT, (b) FT-IR spectrum of mineralized samples by different time without MMT, (c) FT-IR spectrum of mineralized samples by different $\mathrm{Ca}^{2+}$ concentration with MMT, and (d) FT-IR spectrum of mineralized samples by different time with MMT.

Table 2 lists the inner electron binding energy data for mineralized samples with MMT and without MMT. From the X-ray photoelectron spectroscopy (XPS) of O1s (Figures 6(a) and 6(b)), it was found the O1s electron binding energy was $522.87 \mathrm{eV}$ in the XPS spectrum without MMT, but in the MMT system, it reduced to $520.62 \mathrm{eV}$. And the Ca2p electron binding energy shifted from $349.49 \mathrm{eV}$ to $332.17 \mathrm{eV}$ in the mineralized sample system with MMT, and the peak intensity was changed greatly. It can be explained by the fact that MMT and $\mathrm{Ca}^{2+}$ played a certain regulatory role in the microbial mineralization of calcium carbonate crystals, which is consistent with the redshift of the characteristic peaks of $\mathrm{CO}_{3}{ }^{2-}$.

The chemical shift of the X-ray photoelectron spectroscopy is a reflection of the change in the electronic environment surrounding the electron binding energy of the inner layer. In the formation of complexes, the nonbond orbital of the donor undergoes electron charge transfer to the unoccupied orbital of the acceptor, which inevitably exhibits an increase in the electron binding energy of the donor atoms and a decrease in the electron binding energy of the acceptor atoms. It can be seen that the Ols electron binding energy $(2.25 \mathrm{eV})$ in the $\mathrm{C}=\mathrm{O}$ group is lower than mineralized sample system with MMT, and the coordination of O1s and Ca2p leads to the change of O1s' electron binding energy. At the same time, the electron binding energy of Ca2p changed greatly, which decreased by $17.32 \mathrm{eV}$. This seems to be a reflection of the greater impact of MMT on the filling of Ca2p electrons by subfitting of O1s and Ca2p, respectively. In the mineralized sample system without MMT, O1s mainly existed in two chemical states (Figure 6(c)), and the binding energies of O1s were $531.8 \mathrm{eV}$ and $532.8 \mathrm{eV}$, respectively. Ca2p also had two chemical states (Figure 6(e)), and the binding energies of $\mathrm{Ca} 2 \mathrm{p}$ were $347.5 \mathrm{eV}$ and $350.8 \mathrm{eV}$. In the mineralized sample system with MMT, the binding energies of O1s were changed to $531.1 \mathrm{eV}$ and $532.0 \mathrm{eV}$ (Figure 6(d)), and the binding energies of Ca2p were $346.6 \mathrm{eV}$ and $350.5 \mathrm{eV}$ (Figure 6(e)), respectively. This is probably due to the fact that MMT and 


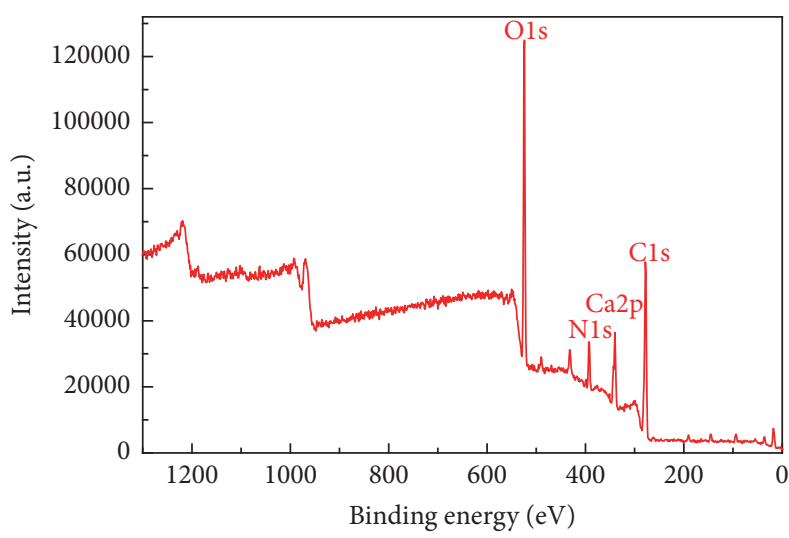

(a)

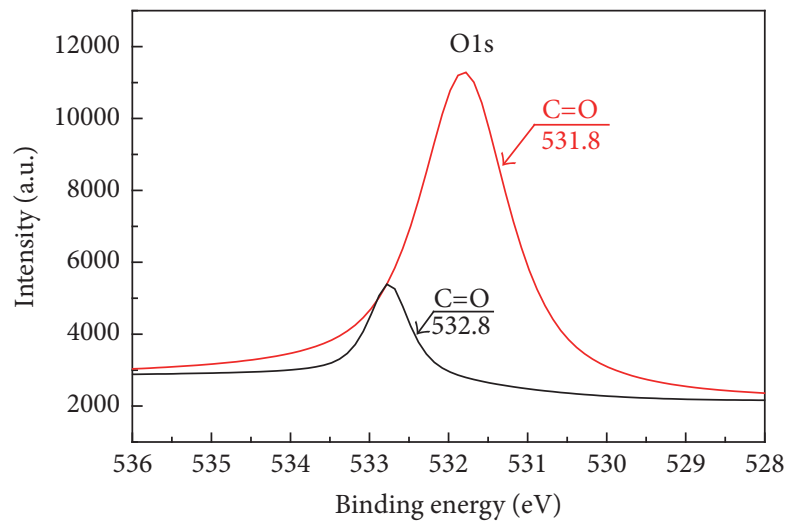

(c)

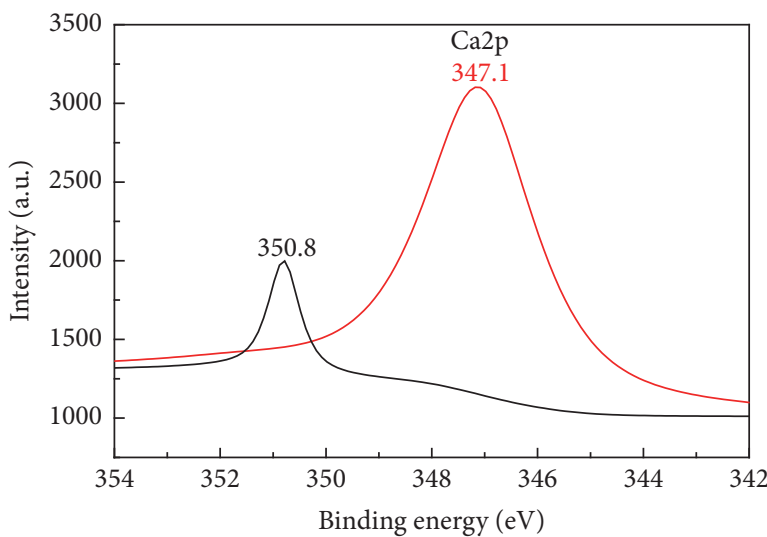

(e)

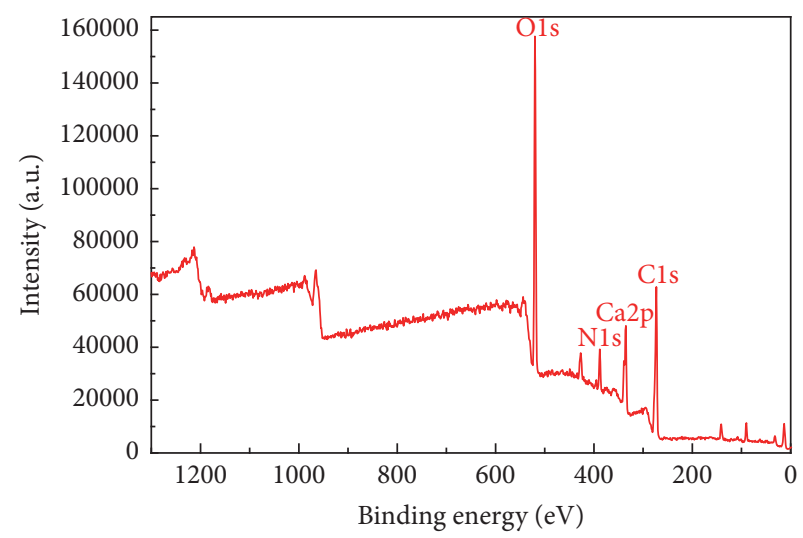

(b)

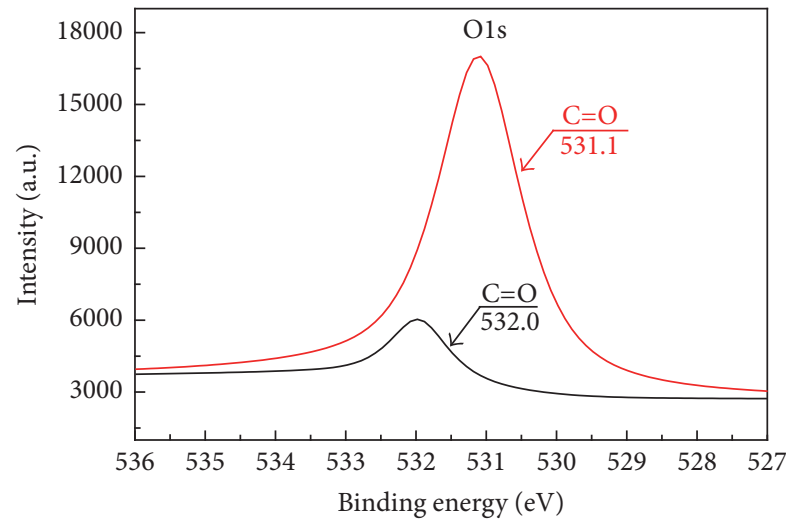

(d)

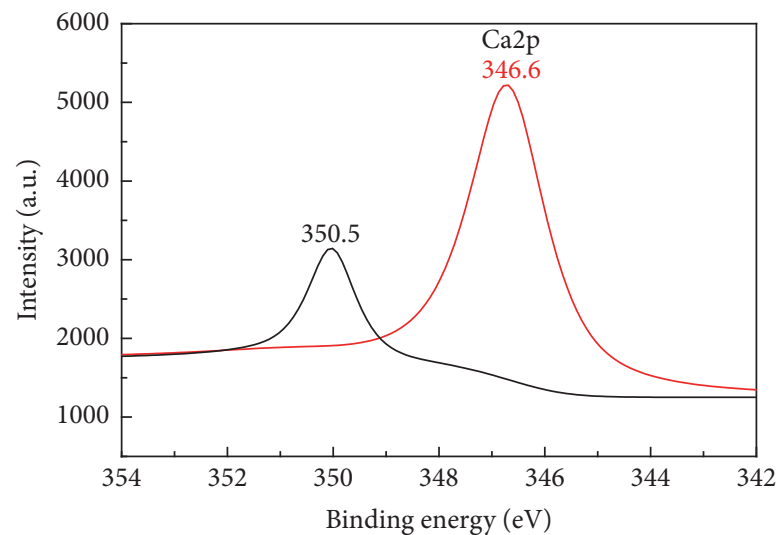

(f)

FIGURE 6: (a) XPS spectrum of mineralized samples without MMT, (b) XPS spectrum of mineralized samples with MMT, (c) XPS spectrum of O1s without MMT, (d) XPS spectrum of O1s with MMT, (e) XPS spectrum of Ca2p without MMT, and (f) XPS spectrum of Ca2p with MMT.

calcium ions have a chemical effect. Furthermore, the MMT involved in microbial mineralization deposition of calcium carbonate process can also explain this behavior.

3.2. Effects of Temperature and $p H$ on Microbial Mineralization. In order to efficiently cement the uranium tailings, we studied the effect of temperature and $\mathrm{pH}$ on microbial mineralization at different temperatures and $\mathrm{pH}$ conditions by varying the number of bacteria and the amount of calcium carbonate produced in the mineralized solution. As can be seen from Figure 7(a), we can see that the number of bacteria in the mineralized solution firstly increased and then decreased, and the number of bacteria reached the maximum at $\mathrm{pH}=8$ with the increase of $\mathrm{pH}$ value. Figure $7(\mathrm{~b})$ shows that the number of bacteria in the mineralized solution increases first and then decreases, and the number of bacteria reaches the maximum at about $30^{\circ} \mathrm{C}$ with the temperature increases. Figures 7(c) and 7(d) show the effect of temperature 


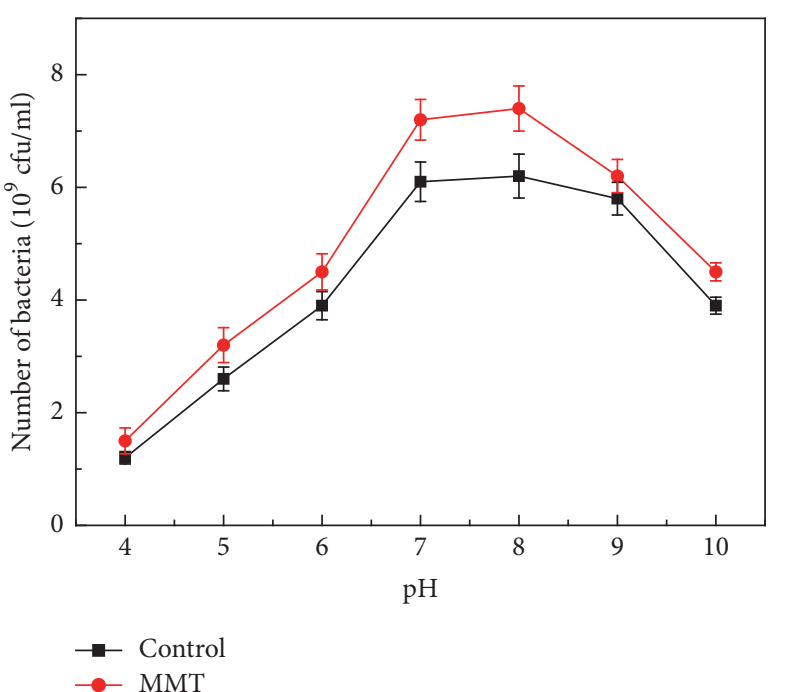

(a)

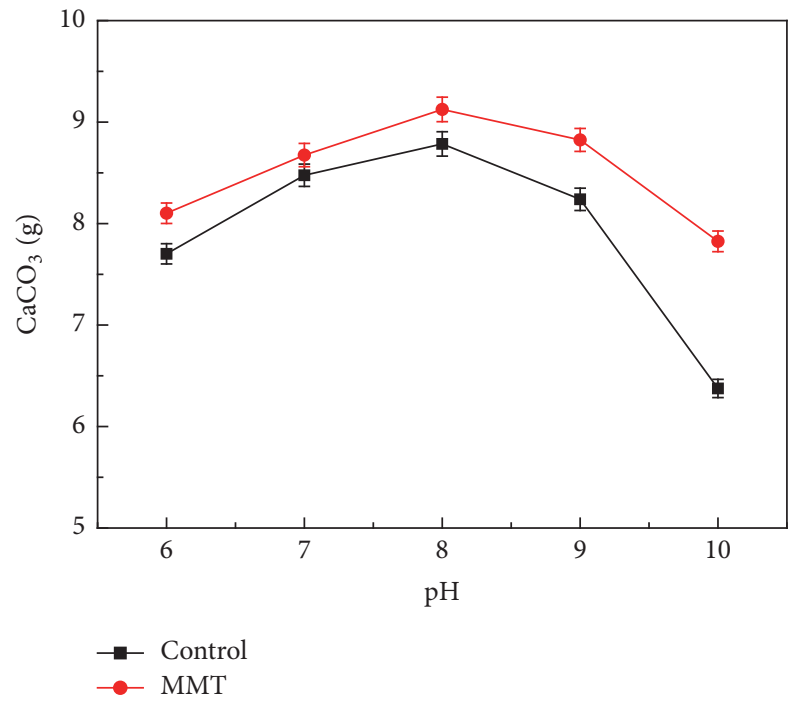

(c)

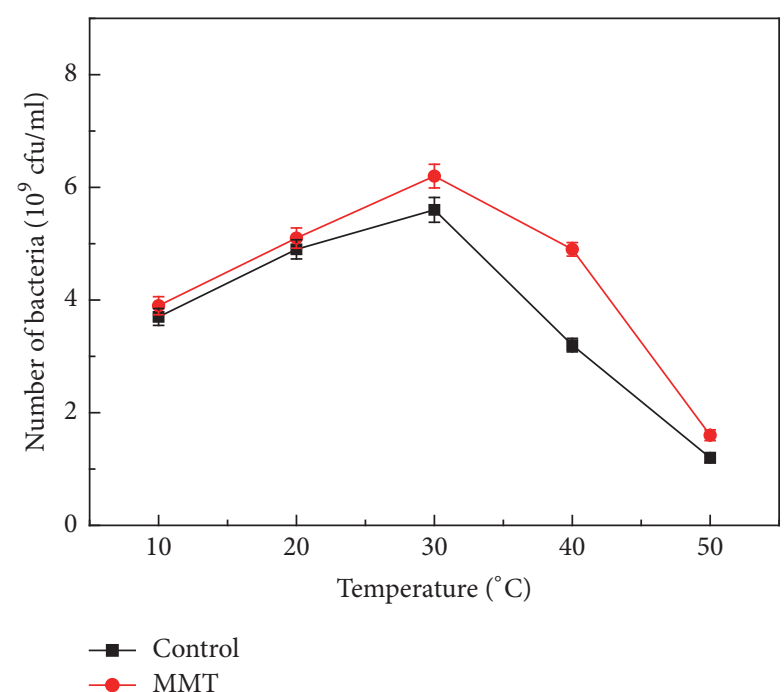

(b)

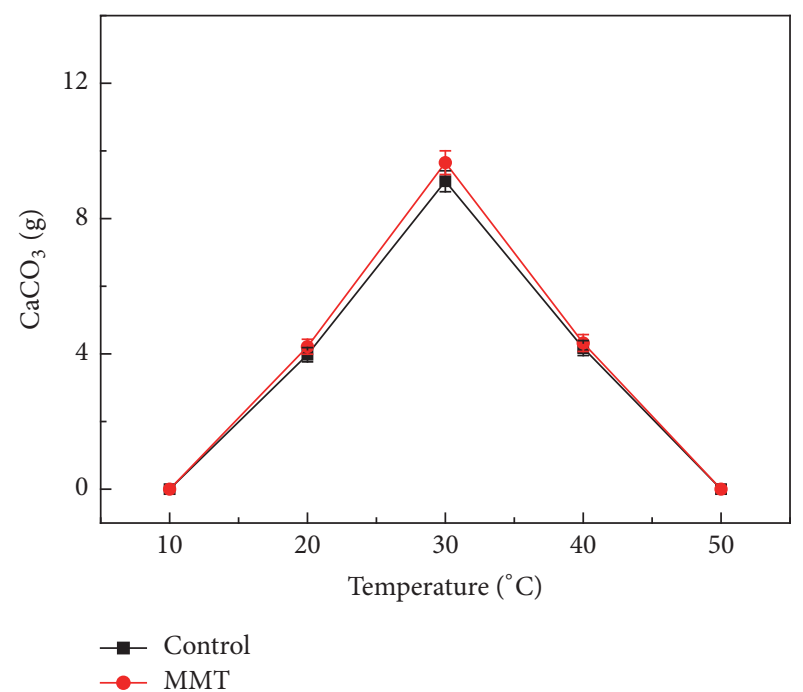

(d)

Figure 7: (a) Effect of $\mathrm{pH}$ on the growth of bacteria, (b) effects of temperature on the growth of bacteria, (c) effect of pH on the yield of $\mathrm{CaCO}_{3}$, and (d) effect of temperature on the yield of $\mathrm{CaCO}_{3}$.

and $\mathrm{pH}$ on the amount of calcium carbonate produced by microorganisms. It can be seen from Figure 7(c) that the amount of calcium carbonate reaches a maximum at $\mathrm{pH}=8$. It can be seen from Figure $7(\mathrm{~d})$ that there is no calcium carbonate precipitation at 0 and $50^{\circ} \mathrm{C}$, and it reaches the maximum at about $30^{\circ} \mathrm{C}$. In addition, the amount of bacteria in the mineralization solution of montmorillonite was significantly higher than the control group, and the amount of calcium carbonate produced was significantly larger than the control group. So we can conclude that MMT for microbial mineralization process has a certain role in promoting. From the above analysis, it can be concluded that the activity of bacteria is the best at a temperature of $30^{\circ} \mathrm{C}$ and the $\mathrm{pH}$ value is 8 . The above conclusions can provide the best conditions for the subsequent microbial mineralization of uranium tailings.
3.3. The Mechanism of MMT Fixed Microbial Solidification of Uranium Tailings. Microbial-induced calcium carbonate mineralization deposition is considered to be a more complex process than chemical action to induce calcium carbonate deposition. The surface of the microbial cell contains many ions which are capable of inducing mineral precipitation by providing a nucleation site [30]. As shown in Figure 8, microbes can produce a large number of urea hydrolases with high activity in their own metabolic activity. They can use urea as a nutrient source in the culture medium, produce ammonia, and carbon dioxide, so that the solution of $\mathrm{CO}_{3}{ }^{2-}$ concentration is increased. Resulting in a slight increase in the $\mathrm{pH}$ value of the solution, more conducive to the growth and reproduction of the cells, the role of enzyme has also been continuously enhanced. At the same time, the negatively charged water-soluble organic matter at 


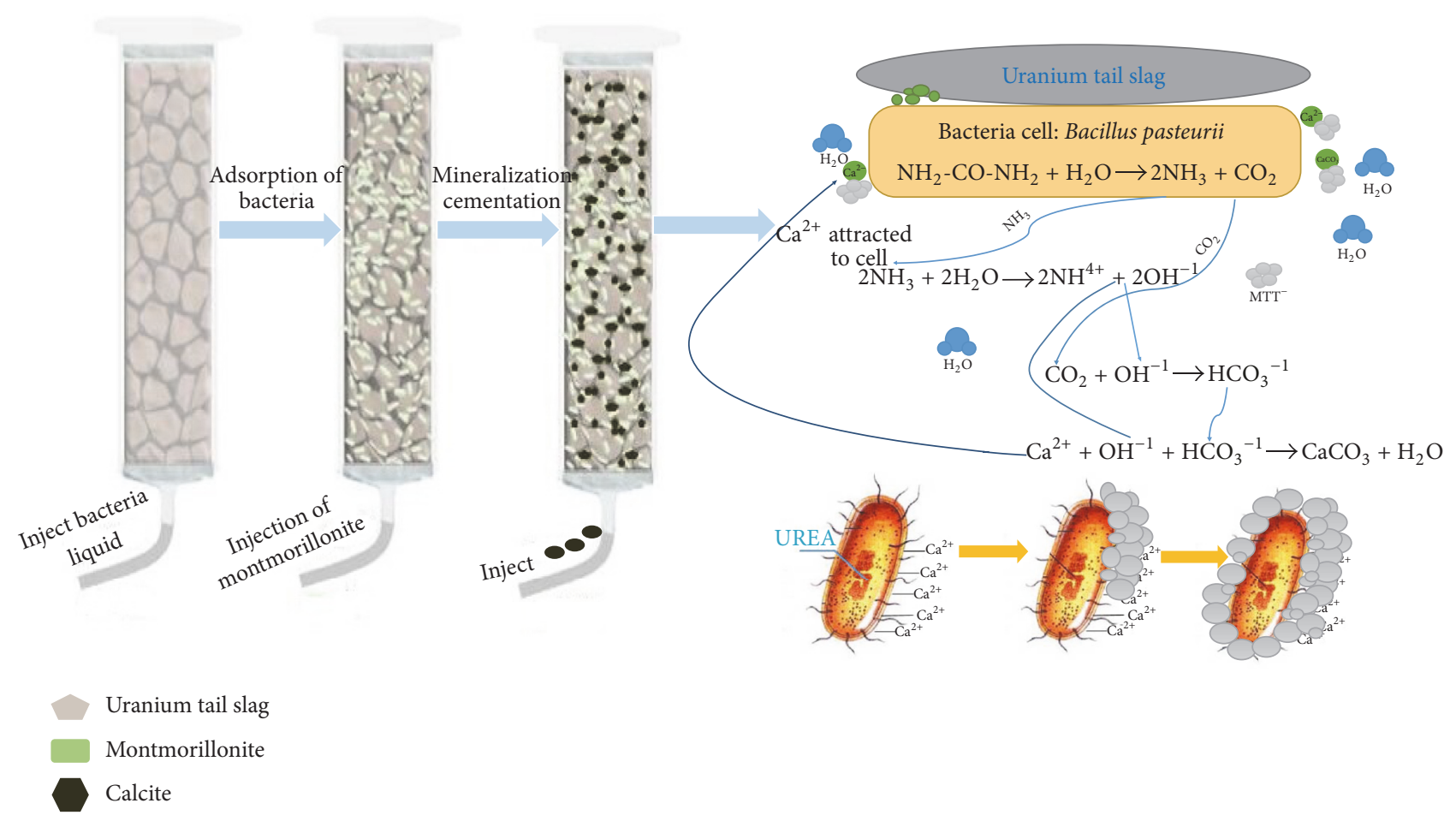

FIGURE 8: Schemes for uranium tailings mineralized by bacteria.

the interface of the cell membrane began to chelate $\mathrm{Ca}^{2+}$, and the concentration of local crystal anions $\left(\mathrm{CO}_{3}{ }^{2-}\right)$ was further increased, microorganism itself as a nucleation site to form calcium carbonate crystals when the concentration of amorphous calcium carbonate precursors reaches saturation. Due to the fact that montmorillonite itself shows negative charge, MMT can be chelated with calcium ions to form chelated calcium ions, chelating calcium ions interact with microorganisms to form calcium carbonate mineral crystals [27]. What is more, MMT can balance the acidity and ions in the uranium tailings (Supporting Information, Figure S2), and it also can reduce the toxicity of uranium ions on microorganisms (Supporting Information, Figure S3) [31]. In addition, MMT filling in the gap between the uranium tailings made the cement body more stable. With the increase of mineralization time, calcium carbonate crystals fill the gap between the uranium tailings, the uranium tailings particles tightly stick together, so that the uranium tail slags into a high strength cement pillar [32].

\subsection{4 Microbial Mineralization of Uranium Tailings. As can} be seen from Figure 9(a), uranium tailings migrated from the loose particles into certain strength of the cement pillar with the mineralization time increased. Figure $9(\mathrm{~b})$ is the cemented sand column by adding different amounts of MMT. Figures 9(c)-9(f) depict the SEM images of the cemented sand column.

Figures 9(d)-9(f) are a cemented sand column by adding MMT. Compared with the cemented column without MMT, the uranium tailings in cemented sand column were combined much tighter because of the presence of MMT (Figure 9(c)). In addition, there are dense calcium carbonate crystals which are formed at the gap among the uranium tailings in cemented sand column. As can be seen from Figures 9(c)-9(f), uranium tailings would be cemented sand column whether MMT was added, but MMT can make cement pillar more compact.

The XRD patterns in Figure 10 show that the composition of cemented sand column contains not only $\mathrm{SiO}_{2}$ but also obvious $\mathrm{CaCO}_{3}$ peak, where calcite and vaterite are present at (104), (113), (202), and (118). With the increase of the amount of MMT, the characteristic peak of calcite gradually increased. We speculate that MMT may be carried out on the retention of radionuclides by good adsorption and ion exchange; thereby it can reduce the toxicity of radionuclides to bacteria.

It can be seen from Figure 11 that with the increase of the amount of MMT, the compressive strength of cemented sand column increases. And when the content of MMT is $6 \%$, the compressive strength reaches the maximum value, the compressive strength of $2.18 \mathrm{MPa}$, which increased by $47.66 \%$ compared with the sample without MMT. The compressive strength of the cement body gradually decreased due to the calcium carbonate crystal which could not penetrate inward with the increase of the amount of MMT, which showed that calcium carbonate crystals form a dense calcium carbonate film on the periphery of the cemented body, thereby preventing the cementation of the internal uranium tailings. 


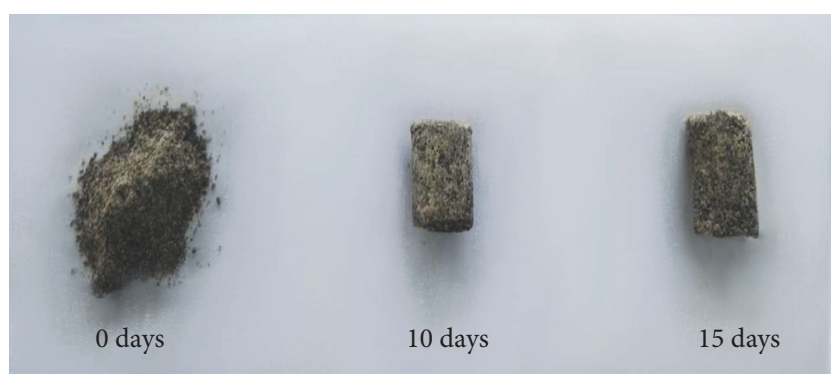

(a)

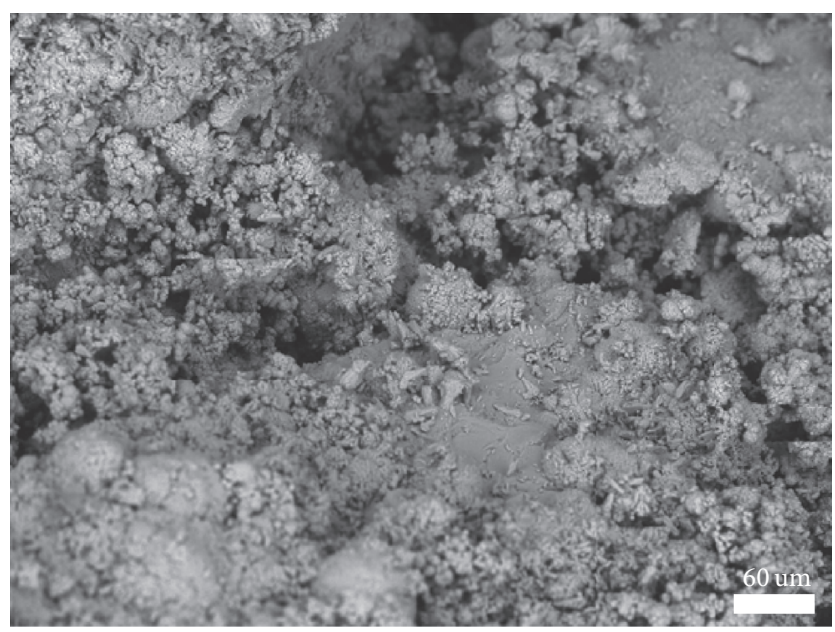

(c)

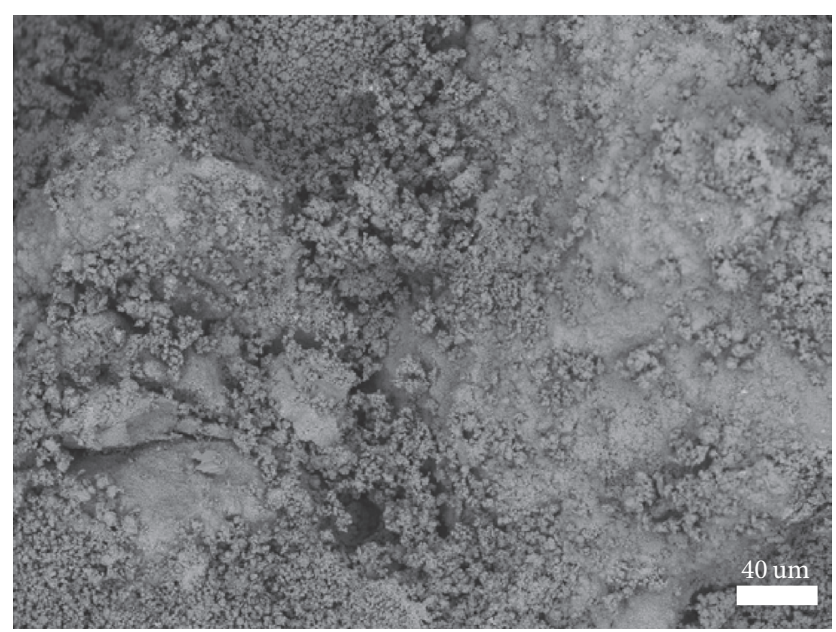

(e)

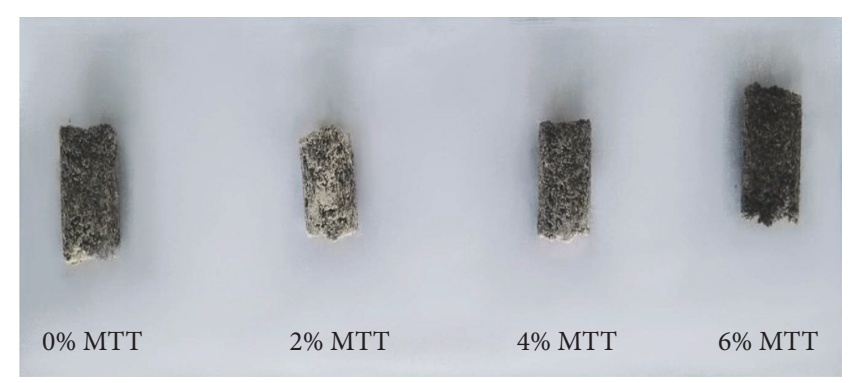

(b)

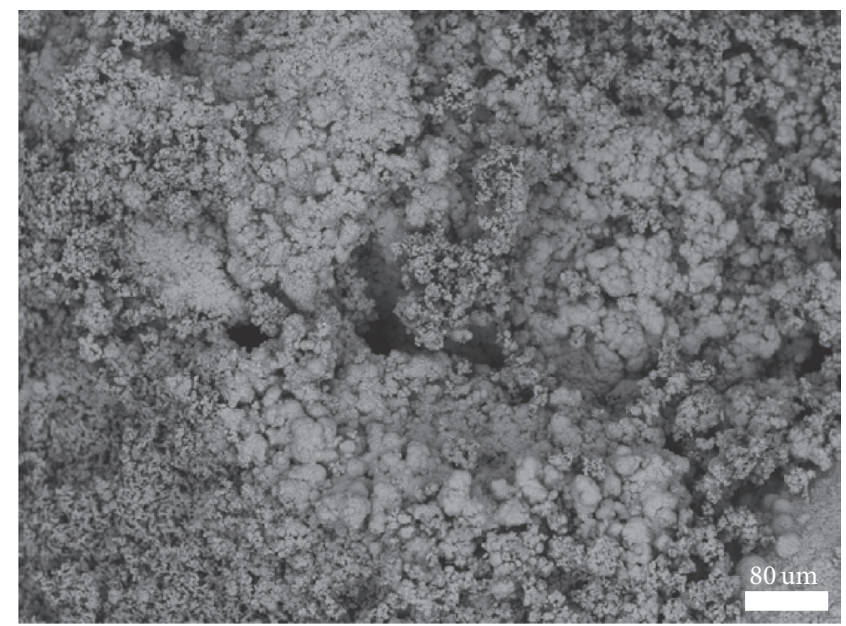

(d)

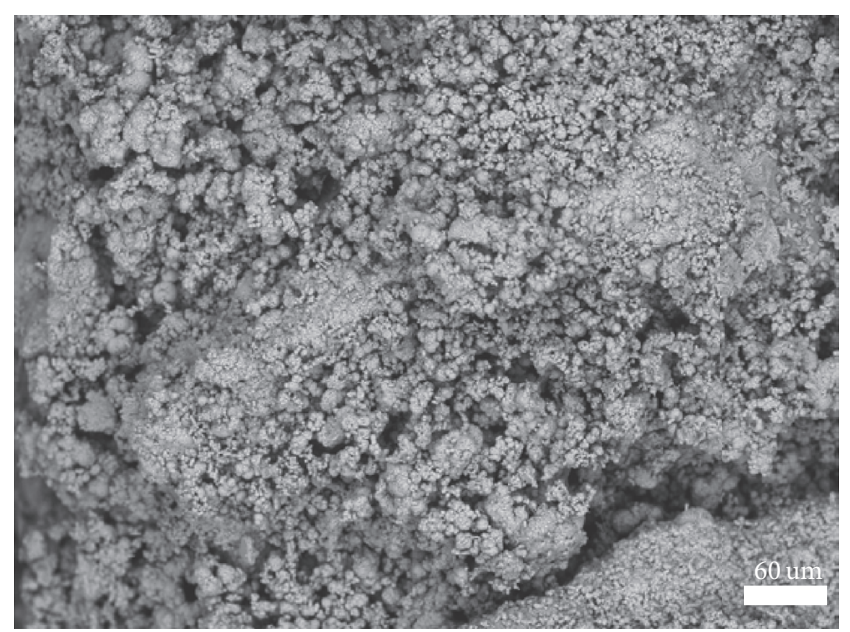

(f)

FIGURE 9: (a) The cemented sand column under different time conditions, (b) the cemented sand column by adding different amounts of MMT, and (c-f) typical SEM images of cemented sand column.

\section{Conclusions}

Based on microbial mineralization cementation of uranium tailings, the results from SEM, FT-IR, XRD, TGA, and XPS and the compression tests indicated that MMT and microbes have some kinds of interaction, to a certain extent, which can regulate the crystal form of calcium carbonate. In addition, MMT negatively charged can be combined with calcium ions to form chelated calcium ions, promoting the formation of calcium carbonate crystals. In the process of microbial mineralization cementation of uranium tailings, MMT can balance the $\mathrm{pH}$ and ions in the uranium tailings; it also can reduce the toxicity of uranium ions on microorganisms. The compressive strength of the cemented sand column with MMT was significantly improved by comparison with the cemented sand column without adding MMT, which indicated that the MMT played a certain role in the microbial 


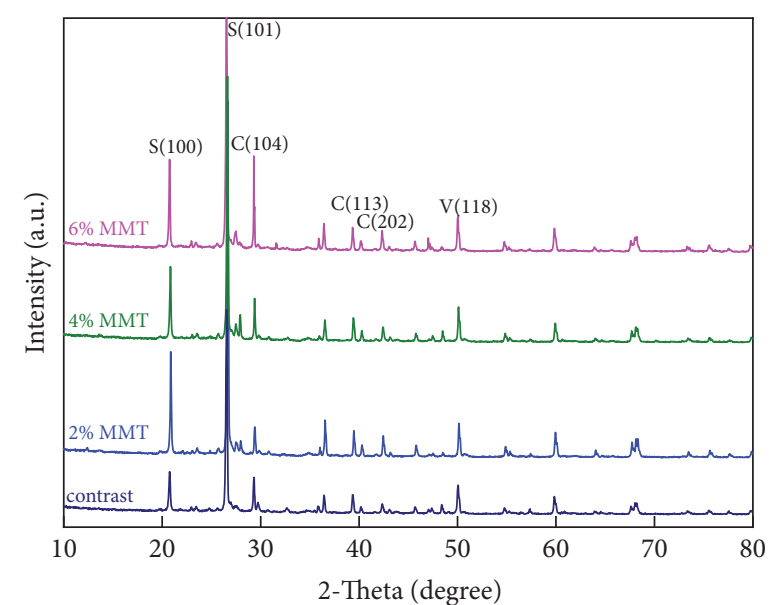

S: $\mathrm{SiO}_{2}$

C: calcite

$\mathrm{V}$ : vaterite

FIGURE 10: XRD patterns of cemented sand column.

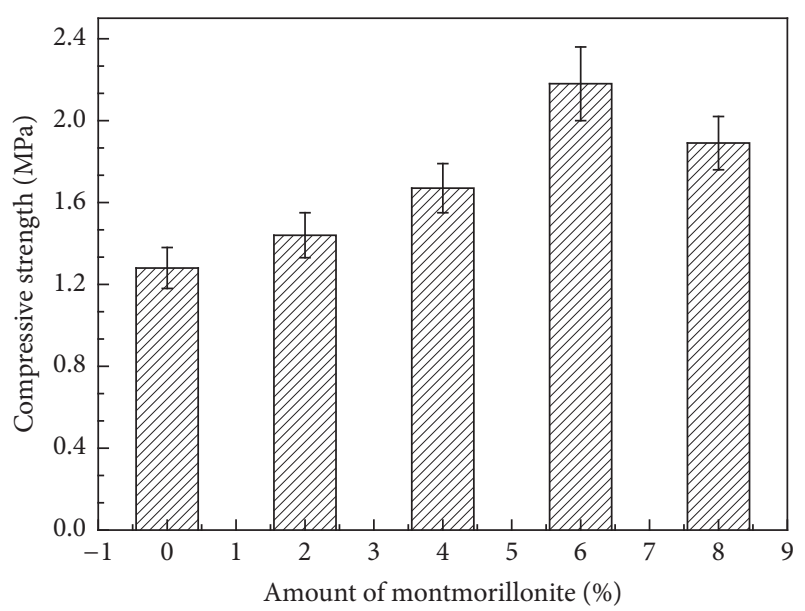

FIGURE 11: Compressive strength of cemented sand column with different concentrations of MMT.

mineralization of the uranium tailings. As can be seen from the above it is reasonable and feasible to induce the deposition of biocalcium carbonate cemented uranium tailings by carbonate mineralization microbe. The analysis results can provide the basis for the theoretical research and practical application of uranium tailings.

\section{Conflicts of Interest}

The authors declare that they have no conflicts of interest.

\section{Acknowledgments}

This work was financially supported by Fundamental Science on Nuclear Wastes and Environmental Safety Laboratory (nos. 14zxnk02 and 15kffk02), Sichuan Province Science and Technology Pillar Program (no. 2014GZ0185),
National Natural Science Foundation of China (nos. 21601147 and 21406182), Key Research and Development Project of Science and Technology Department of Sichuan Province (no. 2017GZ0342), Projects in the Sichuan Province Science and Technology Pillar Program (nos. 2016GZ0259 and 2016GZ0277), and Plan Projects of Mianyang Science and Technology (nos. 15zd2110 and 15zd2102). The authors acknowledge the Southwest University of Science and Technology Analysis and Testing Center for the help of sample testing.

\section{References}

[1] G. M. Gadd, "Metals, minerals and microbes: geomicrobiology and bioremediation," Microbiology, vol. 156, no. 3, pp. 609-643, 2010.

[2] M. Kawano and K. Tomita, "Geochemical modeling of bacterially induced mineralization of schwertmannite and jarosite in sulfuric acid spring water," American Mineralogist, vol. 86, no. 10, pp. 1156-1165, 2001.

[3] E. Joussein, S. Petit, J. Churchman, B. Theng, D. Righi, and B. Delvaux, "Halloysite clay minerals-a review," Clay Minerals, vol. 40, no. 4, pp. 383-426, 2005.

[4] J. M. Hammarstrom, R. R. Seal II, A. L. Meier, and J. M. Kornfeld, "Secondary sulfate minerals associated with acid drainage in the eastern US: Recycling of metals and acidity in surficial environments," Chemical Geology, vol. 215, no. 1-4, pp. 407-431, 2005.

[5] B. Biswas, B. Sarkar, R. Rusmin, and R. Naidu, "Bioremediation of PAHs and VOCs: Advances in clay mineral-microbial interaction," Environment International, vol. 85, pp. 168-181, 2015.

[6] L. Shi, H. Dong, G. Reguera et al., "Extracellular electron transfer mechanisms between microorganisms and minerals," Nature Reviews Microbiology, vol. 14, no. 10, pp. 651-662, 2016.

[7] F. Mapelli, R. Marasco, A. Balloi et al., "Mineral-microbe interactions: Biotechnological potential of bioweathering," Journal of Biotechnology, vol. 157, no. 4, pp. 473-481, 2012.

[8] H. R. Beller, "Anaerobic, nitrate-dependent oxidation of $\mathrm{U}(\mathrm{IV})$ oxide minerals by the chemolithoautotrophic bacterium Thiobacillus denitrificans," Applied and Environmental Microbiology, vol. 71, no. 4, pp. 2170-2174, 2005.

[9] G. J. Pronk, K. Heister, C. Vogel et al., "Interaction of minerals, organic matter, and microorganisms during biogeochemical interface formation as shown by a series of artificial soil experiments," Biology and Fertility of Soils, vol. 53, no. 1, pp. 922, 2017.

[10] D. R. Brookshaw, R. A. D. Pattrick, J. R. Lloyd, and D. J. Vaughan, "Microbial effects on mineral-radionuclide interactions and radionuclide solid-phase capture processes," Mineralogical Magazine, vol. 76, no. 3, pp. 777-806, 2012.

[11] M. I. Boyanov, D. E. Latta, M. M. Scherer, E. J. O’Loughlin, and K. M. Kemner, "Surface area effects on the reduction of UVI in the presence of synthetic montmorillonite," Chemical Geology, vol. 464, pp. 110-117, 2016.

[12] H. Du, W. Chen, P. Cai et al., "Cd(II) Sorption on Montmorillonite-Humic acid-Bacteria Composites," Scientific Reports, vol. 6, Article ID 19499, 2016.

[13] L. Jiang, J. Zhu, H. Wang et al., "Sorption of humic acid on Fe oxides, bacteria, and Fe oxide-bacteria composites," Journal of Soils and Sediments, vol. 14, no. 8, pp. 1378-1384, 2014. 
[14] Z. Miao, H. N. Akyol, A. L. McMillan, and M. L. Brusseau, "Transport and fate of ammonium and its impact on uranium and other trace elements at a former uranium mill tailing site," Applied Geochemistry, vol. 38, pp. 24-32, 2013.

[15] E. Boquet, A. Boronat, and A. Ramos-Cormenzana, "Production of calcite (Calcium carbonate) crystals by soil bacteria is a general phenomenon," Nature, vol. 246, no. 5434, pp. 527-529, 1973.

[16] H. Dong and A. Lu, "Geomicrobiology Research in China: Mineral-Microbe Interactions," Geomicrobiology Journal, vol. 29, no. 3, pp. 197-198, 2012.

[17] H. Dong, "Mineral-microbe interactions: A review," Frontiers of Earth Science in China, vol. 4, no. 2, pp. 127-147, 2010.

[18] H. A. Lowenstam, "Minerals formed by organisms," Science, vol. 211, no. 4487, pp. 1126-1131, 1981.

[19] D. Kim, K. Park, and D. Kim, "Effects of ground conditions on microbial cementation in soils," Materials, vol. 7, no. 1, pp. 143156, 2014.

[20] J. T. DeJong, M. B. Fritzges, and K. Nüsslein, "Microbially induced cementation to control sand response to undrained shear," Journal of Geotechnical and Geoenvironmental Engineering, vol. 132, no. 11, pp. 1381-1392, 2006.

[21] L. A. van Paassen, R. Ghose, T. J. M. van der Linden, W. R. L. van der Star, and M. C. M. van Loosdrecht, "Quantifying biomediated ground improvement by ureolysis: Large-scale biogrout experiment," Journal of Geotechnical and Geoenvironmental Engineering, vol. 136, no. 12, pp. 1721-1728, 2010.

[22] J. Wang, K. Van Tittelboom, N. De Belie, and W. Verstraete, "Use of silica gel or polyurethane immobilized bacteria for selfhealing concrete," Construction and Building Materials, vol. 26, no. 1, pp. 532-540, 2012.

[23] W. Zhu, T. Mu, T. Duan, Y. Zhang, and X. Luo, "Optimization for microbiological-induced $\mathrm{CaCO}_{3}$ precipitation medium using response surface methodology," Chemical Industry and Engineering Progress, vol. 33, no. 6, pp. 1533-1538, 2014.

[24] P. J. M. Smeets, K. R. Cho, R. G. E. Kempen, N. A. J. M. Sommerdijk, and J. J. De Yoreo, "Calcium carbonate nucleation driven by ion binding in a biomimetic matrix revealed by in situ electron microscopy," Nature Materials, vol. 14, no. 4, pp. 394399, 2015.

[25] S. Aldea, M. Snåre, K. Eränen et al., "Crystallization of NanoCalcium Carbonate: The Influence of Process Parameters," Chemie-Ingenieur-Technik, vol. 88, no. 11, pp. 1609-1616, 2016.

[26] W. Xie, Z. Gao, W.-P. Pan, D. Hunter, A. Singh, and R. Vaia, "Thermal degradation chemistry of alkyl quaternary ammonium Montmorillonite," Chemistry of Materials, vol. 13, no. 9, pp. 2979-2990, 2001.

[27] W. Zhu, T. Mu, Y. Zhang, T. Duan, and X. Luo, "Coating of microbially produced calcium carbonate onto stone materials," Science China Technological Sciences, vol. 58, no. 2, pp. 266-272, 2014.

[28] M. A. Lopez-Heredia, A. Łapa, A. C. Mendes et al., "Bioinspired, biomimetic, double-enzymatic mineralization of hydrogels for bone regeneration with calcium carbonate," Materials Letters, vol. 190, pp. 13-16, 2017.

[29] H. Wang, L. Tang, X. Wu, W. Dai, and Y. Qiu, "Fabrication and anti-frosting performance of super hydrophobic coating based on modified nano-sized calcium carbonate and ordinary polyacrylate," Applied Surface Science, vol. 253, no. 22, pp. 88188824, 2007.
[30] F. G. Ferris, T. J. Beveridge, and W. S. Fyfe, "Iron-silica crystallite nucleation by bacteria in a geothermal sediment," Nature, vol. 320, no. 6063, pp. 609-611, 1986.

[31] H. Dong, D. P. Jaisi, J. Kim, and G. Zhang, "1505-1519 Microbeclay mineral interactions," American Mineralogist, vol. 94, no. 11-12, pp. 1505-1519, 2009.

[32] M. Fall, J. C. Célestin, M. Pokharel, and M. Touré, "A contribution to understanding the effects of curing temperature on the mechanical properties of mine cemented tailings backfill," Engineering Geology, vol. 114, no. 3-4, pp. 397-413, 2010. 

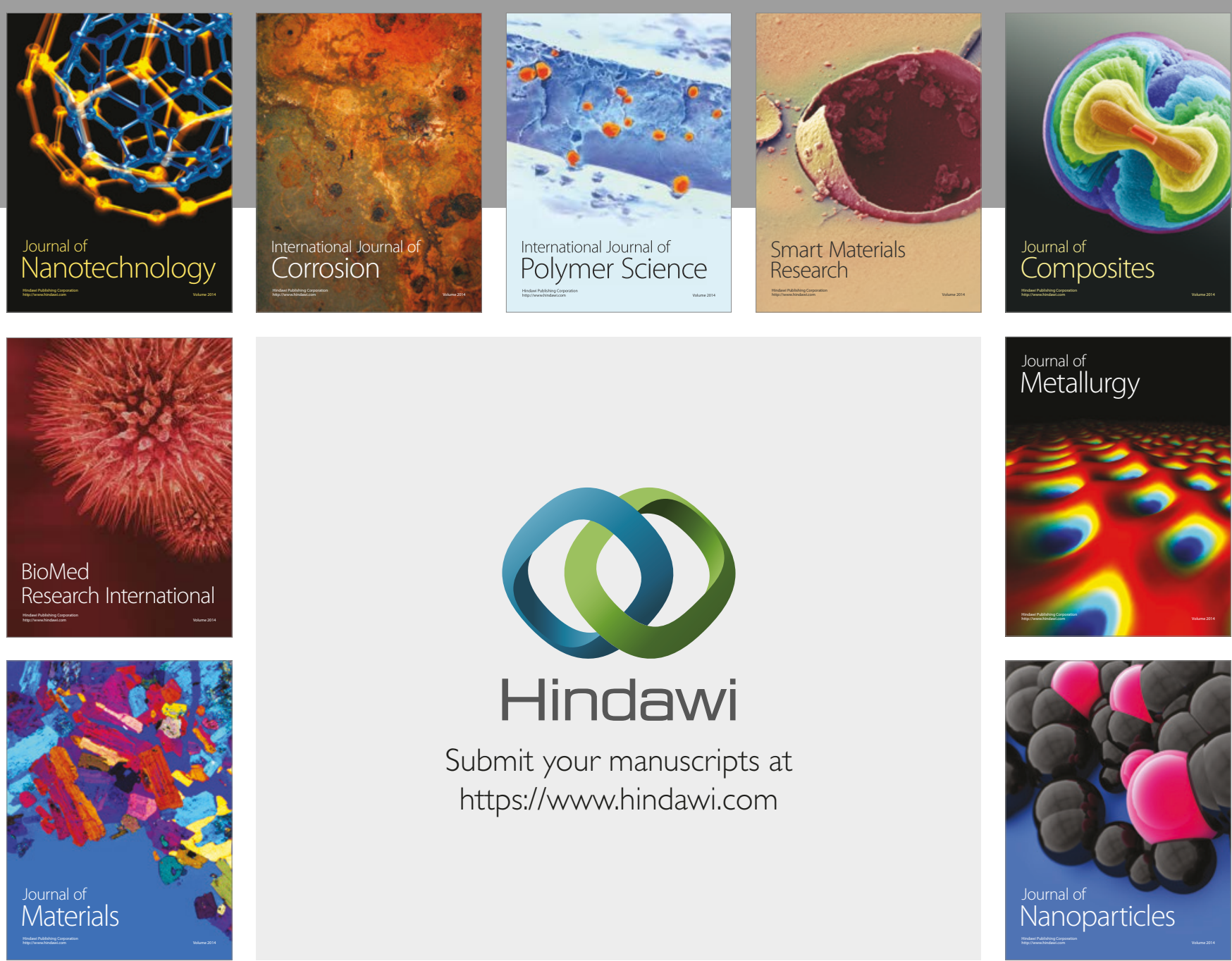

\section{Hindawi}

Submit your manuscripts at

https://www.hindawi.com
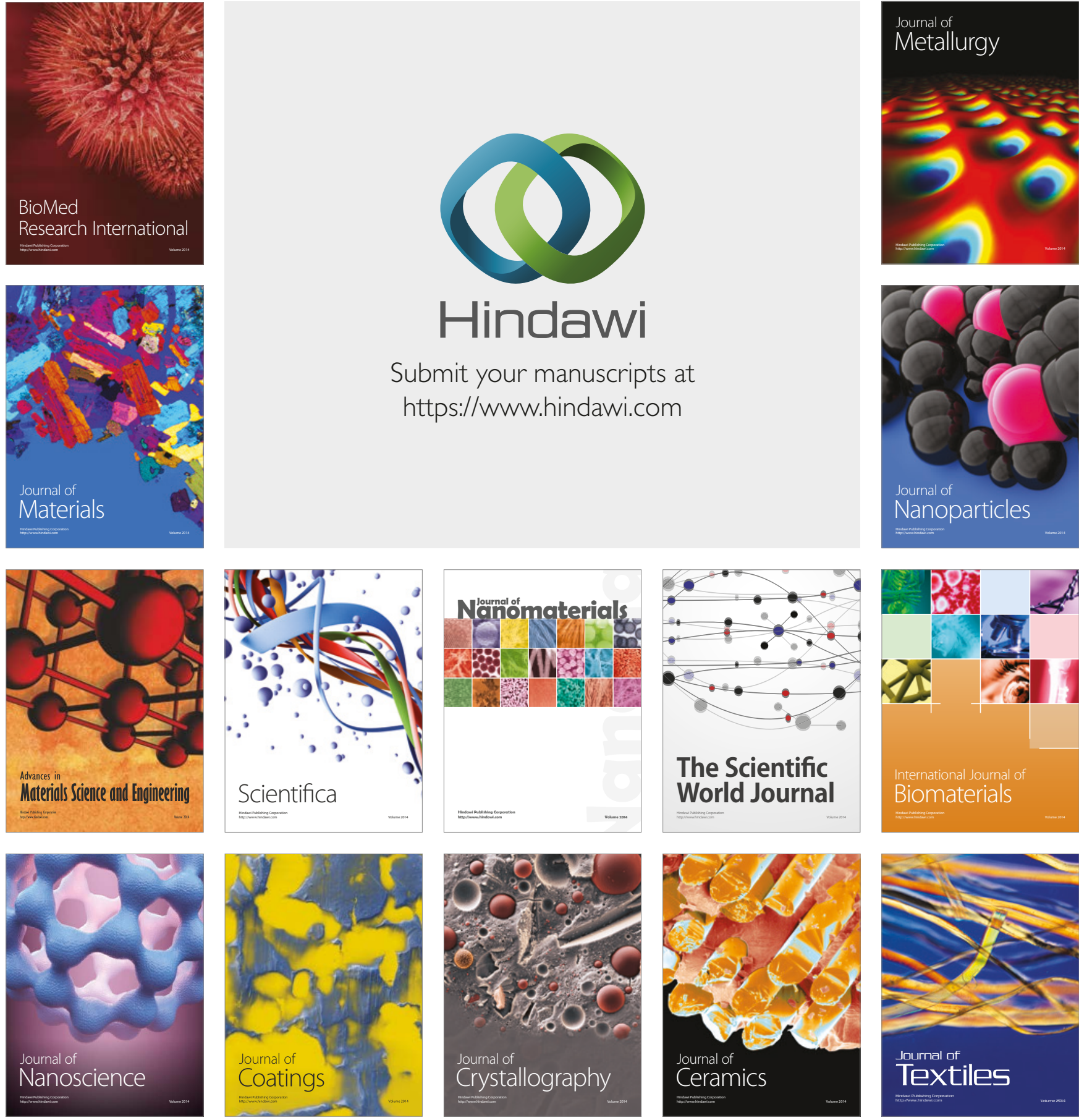

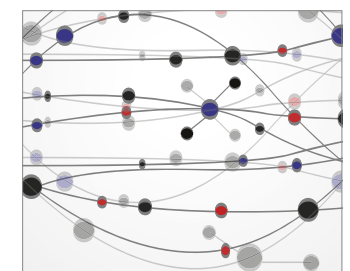

The Scientific World Journal
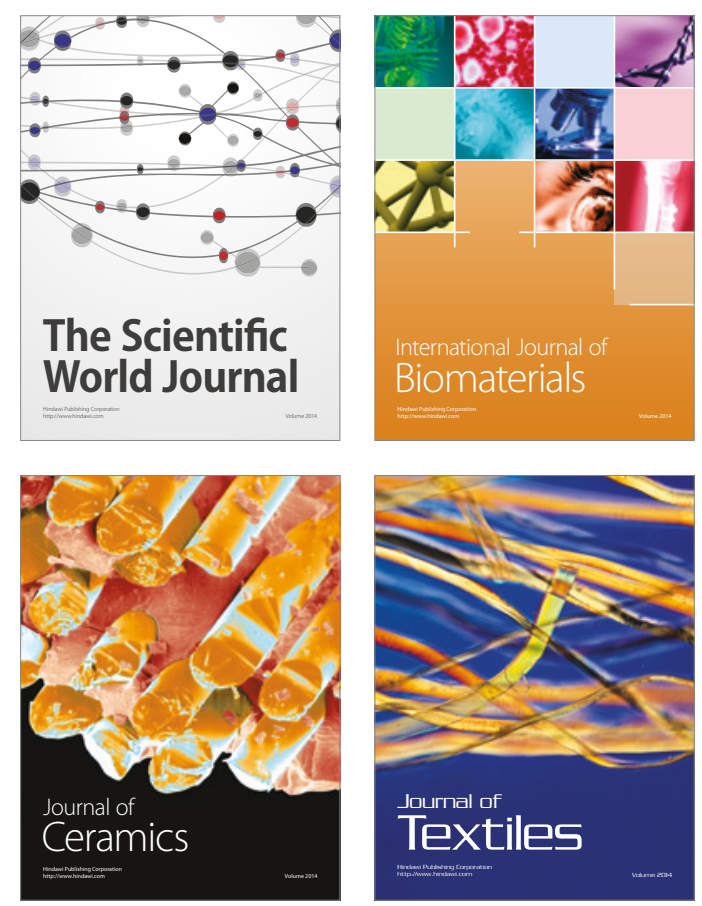